Article

\title{
phyB and HY5 are Involved in the Blue Light- Mediated Alleviation of Dormancy of Arabidopsis Seeds Possibly via the Modulation of Expression of Genes Related to Light, GA, and ABA
}

\author{
Marlena Stawska and Krystyna Oracz *D \\ Department of Plant Physiology, Institute of Biology, Warsaw University of Life Sciences-SGGW, \\ Nowoursynowska str. 159, 02-776 Warsaw, Poland; stawska.marlena@gmail.com \\ * Correspondence: krystyna_oracz@sggw.pl; Tel.: +48-2259-325-35
}

Received: 1 November 2019; Accepted: 20 November 2019; Published: 23 November 2019

\begin{abstract}
Light is one of the most important environmental factors regulating seed germination. It is known that light inhibits seed germination of some monocotyledonous species and that it is mostly related to the blue wavelength of the spectrum received by cryptochromes (cry). Research has also found that the red light $(\mathrm{R})$ stimulates germination of dicotyledonous seeds and that this reaction involves mainly phytochromes (phy). Surprisingly, up to date, the role and the mechanism of action of blue light (BL) in seed biology of dicot plants is still very poorly understood and some questions are unexplained, e.g., whether BL plays a role in regulation of dicot seeds dormancy and/or germination? If, so what particular elements of light signaling pathway are involved in modulation of this(ese) process(es)? Also, is the BL action in regulation of dicot seeds dormancy and/or germination maybe due to changes of expression of genes related to metabolism and/or signaling of two phytohormones controlling seed-related events, such as gibberellins (GA) and abscisic acid (ABA)? To answer these intriguing questions, the combination of biological, transcriptomic, and genetic approaches was performed in this particular study. The germination tests show that freshly harvested wild type (WT) Arabidopsis thaliana Col-0 seeds are dormant and do not germinate in darkness (at $25{ }^{\circ} \mathrm{C}$ ), while nondormant (after-ripened) seeds germinate well in these conditions. It is also proven that dormancy of seeds of this species is released in the presence of white and/or BL $(\lambda=447 \mathrm{~nm})$ when placed at $25^{\circ} \mathrm{C}$. Presented here, novel results emphasize the role of BL in dormancy alleviation of dicot seeds, indicating that this wavelength of light spectrum received by phyB induces this process and that the sensitivity to this stimulus depends on the depth of seed dormancy. In addition, it is demonstrated that various elements of phy-mediated pathway can be used in response to the signal induced by BL in germinating dormant seeds of Arabidopsis. The quantitative real time PCR analysis supported by results of germination tests of WT, T-DNA insertion mutants (i.e., hy5, hfr1, and laf1) and overexpression transformants of Arabidopsis seeds (i.e., 35S:OE:HY5, 35S:OE:HYH, 35S:OE:HFR1, and 35S:OE:LAF1) revealed that the HY5 gene coding transcription factor is most probably responsible for the control of expression of genes involved in GA/ABA metabolism and/or signaling pathways during BL-dependent dormancy alleviation of Arabidopsis seeds, while biological functions of $H Y H$ and HFR 1 are associated with regulation of germination. The model of BL action in regulation of dormancy alleviation and germination potential of Arabidopsis seeds is proposed.
\end{abstract}

Keywords: abscisic acid; cryptochromes; dicot seeds; dormancy alleviation; germination; gibberellins; light; phytochromes; signal transduction; transcription factors 


\section{Introduction}

Environmental factors, such as temperature and light, act as clues for plants during their life cycle [1]. The temperature can inform seeds about the season of the year and may influence dormancy induction and/or alleviation, as well as germination [2]. Due to the fact that small seeds (i.e., of Arabidopsis thaliana) contain a limited amount of storage materials, the influence of light is particularly important for them, as it can bring crucial information on how deep they are placed in the ground and, thus, if the emerging seedlings will be able to grow into mature plants [3]. In nature, the temperature but also quantity, quality, and direction of light signal depend on the season of the year, time of a day, presence of clouds, and even level of air pollution. In the context of continuously increasing scale of devastation of our planet, these factors are becoming recognized as a source of serious problems. The air pollution consists of particles differing in size and chemical structure determining its properties, such as light absorption and scattering, which in consequence may affect plant growth and development. The changes of the environmental temperature due to global warming influence the mother plant, which in consequence alter seed dormancy and germination behavior of various species [4]. The sensitivity to the light of Arabidopsis (ecotype Col-0) seeds characterized by different depth of dormancy is strongly connected with the temperature requirements allowing proper germination [5]. It was reported that, at harvest, this type of seed germinate quite well in darkness, at a range of temperatures from 10 up to $20^{\circ} \mathrm{C}$, but this process is strictly limited at $25^{\circ} \mathrm{C}$. Interestingly, this inhibitory effect of the temperature is alleviated by the presence of white light [5]. Besides the environmental stimuli (i.e., light and temperature), the internal factors (i.e., phytohormones, such as GA and ABA) play a crucial role in modulation of processes occurring in seeds [6,7]. The ABA is a major negative regulator of seed germination, responsible for the induction and maintenance of dormancy, whereas GA have an antagonistic effect to it, as they promote germination. It was proven that the phytohormone contents, signaling, and interactions play important roles in determination of the physiological state of the seed and in regulation of germination process $[6,8,9]$.

Arabidopsis plants possess several light sensors including 1) blue light (BL) photoreceptors, such as two phototropins (phot1 and phot2), ZTL/FKF1/LKP2 proteins (ZEITLUPE; FLAVIN-BINDING, KELCH REPEAT, F-BOX 1; and LOV KELCH PROTEIN 2), LLP BL protein (LOV/LOV domain-containing protein, where LOV is called the light, oxygen, or voltage photosensory domain), three cryptochromes (cry; cry1, cry2); 2) red/far red (R/FR) photoreceptors-five phytochromes (phy), such as phyA, phyB, phyC, phyD, and phyE-and 3) UV-B photoreceptor UVR8 [10-16]. It is known that photoreceptors must be coupled to a biochemical mechanism so that absorption of light energy generates a chemical signal that modifies cellular metabolism and signaling, leading to changes in growth and/or cell differentiation. An increasing number of evidences shows also that signal transduction pathway of light interacts with other paths of endogenous factors, thus possessing a very complicated mechanism of action $[6,15]$. The phy modulates GA and ABA metabolism and signaling through one of their interacting proteins, PIL5 (PIF3-LIKE 5), that is one of 15 basic helix-loop-helix (bHLH) subfamily members in Arabidopsis (including PIFs, PHYTOCHROME INTERACTING FACTORs). It was demonstrated that the seeds of pil5 Arabidopsis mutants germinate even under noninductive light condition, whereas the PIL5 overexpressor requires the higher fluence of light for germination [3].

Light perception by phy and cry primarily suppress many protein-protein interactions including CUL4 COP1-SPAs E3 ubiquitin ligase (CULLIN 4, CONSTITUTIVE PHOTOMORPHOGENIC 1, and SUPRESS PHYTOCHROME A-105) with key targets, such as transcription factors (i.e., HY5, ELONGATED HYPOCOTYL 5; HYH, HY5-HOMOLOG; HFR1, LONG HYPOCOTYL IN FAR-RED 1; and LAF1, LONG AFTER FAR-RED LIGHT 1), resulting in changes in expression profiles of defined genes [16]. Interestingly, the phy photoreceptors encoded by five genes in Arabidopsis (PHYA-PHYE) seem to partially overlap their functions $[10,17]$. The phyB regulates gene expression in response to $R$ light, while phyA regulates under continuous far-red (FR) light. It was also proven that phyA is rapidly destabilized upon R light irradiation by E3 ubiquitin ligases including COP1 [18]. The research studies elucidating the role of phy in germination of dicot seeds highlighted that mainly phyB and phyA regulate 
this process via modulation of expression of genes involved in metabolism of phytohormones, such as GA (i.e., GA2ox2 and GA2ox6 (GA 2-OXIDASE 2 and 6); GA3ox1 and GA3ox2 (GA 3-OXIDASE 1 and 2); and KAO2 (ENT-KAURENOIC ACID OXYDASE 2)), and ABA (i.e., ABA1 (ARABIDOPSIS THALIANA ABA DEFICIENT 1); NCED6 and NCED9 (NINE-CIS EPOXYCAROTENOID DIOXYGENASE 6 and 9); and CYP707A2 (CYTOCHROME P450, FAMILY 707, SUBFAMILY A, POLYPEPTIDE 2)) [2,3,19]. Moreover, the involvement of GA and ABA in the phy-mediated Arabidopsis germination response was also demonstrated $[3,20]$. It is also known that not only the phytohormone content but also its perception and signal transduction determine seed germinability [3]. For the GA signaling pathway, the most important elements seem to be DELLA factors (including RGL-REPRESSOR OF GA-LIKE genes) and GID1 (GA INSENSITIVE DWARF 1) receptors. The presence of GA enables GID1 activation and formation of the GID1-DELLA complex, which leads to rapid DELLA degradation [21]. The DELLA proteins may also mediate interaction between GA and ABA pathways because one of its targets, XERICO (RING/U-box superfamily protein) regulates ABA metabolism [22]. In plant cells, among the key elements forming the ABA signaling pathway are PYR/PYL/RCAR receptors of ABA (PYRABACTIN RESISTANCE/PYR1-LIKE/REGULATORY COMPONENT OF ABA RECEPTOR); protein phosphatases type 2C (PP2C) encoded by HAI1, 2, and 3 genes (HIGHLY ABA-INDUCED $P P 2 C$ 1, 2, and 3); SNF1-related protein kinases 2 (SnRK2); and ABI transcription factors coded by $A B A$ INSENSITIVE genes [23].

Similar to phy, cry also has some diverse and overlapping functions. Although cry signaling pathway seems to be complicated and involves many different signaling proteins, it relies on two main protein-protein interactions. The first leads through cry1 and its interactions with SPA1 protein [24,25]. The SPA1 protein interacts with COP1 in the dark and positively regulates COP1 activity. In addition, COP1 activity may be regulated by interaction with PIF1, which enhances activity of the COP1/SPA complex in darkness [16]. The COP1-SPA1 complex acts as the substrate adaptor of the CUL4COP1-SPAs E3 ubiquitin ligase responsible for ubiquitination and proteasomal degradation of specific proteins, such as HY5, HYH, HFR1, and LAF1 [26]. In consequence, the influence of cry1 on COP1 enables modulation of specific light-related gene expression [25]. The other method of cry action is through their interactions with transcription factors from the CIB (CRYPTOCHROME INTERACTING BASIC HELIX-LOOP-HELIX) family. There are evidences that cry2 by physical interactions with CIB1 and CIB5 can influence, for example, expression of FT (FLOWERING LOCUS T) and can therefore affect floral initiation in Arabidopsis plants [27]. Despite many researches, the physiological function and mechanism of action of cry3 remains unclear and requires future investigation. However, taking into account its biochemical activity in repair of ss-DNA, it was suggested that cry3 may be involved in protection of organellar genomes in Arabidopsis against UV damage [14].

The role of the R light and phy in seed biology of dicot plants as well as the BL and cry in seeds germination of monocot species is quite well understood. The BL plays an important role in dormancy induction of freshly harvested cereal grains while the R/FR spectra regulate germinability of many species of dicot seeds including Arabidopsis $[3,7,20,28,29]$. Surprisingly, the function of the BL and light signaling in dormancy and germination of dicot seeds is still very elusive. Therefore, the aim of this study was to characterize the role of BL and particular components of cry/phy-mediated signaling pathways in the regulation of light-dependent germination of dormant Arabidopsis seeds. The following research questions were stated: (1) What is the role of BL in regulation of germination of Arabidopsis seeds characterized by different depth of dormancy? (2) Which of the cry/phy photoreceptors and/or which elements of the $\mathrm{BL} / \mathrm{R} / \mathrm{FR}$ light signaling pathways participate in the response of the germinating seeds to the BL stimulus? (3) Does the BL-induced signal use particular elements of the phy-mediated pathway? (4) If so, is the regulation of germinability of Arabidopsis dormant and/or nondormant seeds by the BL associated with the modulation of the expression of genes related to metabolism and/or signaling of ABA/GA? The biological assays preformed in this study indicated that freshly harvested Arabidopsis (Col-0) wild type (WT) seeds were dormant, as they did not germinate in darkness at $25^{\circ} \mathrm{C}$, while the presence of $\mathrm{BL}$ and white light had a stimulating effect on this process. To verify 
whether genes related to phy/cry signaling pathways as well as genes related to GA/ABA metabolism and/or signal transduction might be involved in BL-dependent regulation of dormant Arabidopsis seed germination, changes in their relative expression during germination of dormant seeds exposed to different light conditions were investigated using the qRT-PCR method. Obtained results emphasize the role of BL in the regulation of dormancy alleviation of dicot seeds, indicating that cry- and phymediated signaling pathways may regulate this process in a light- and dormancy-dependent manner by modulation of transcript levels of genes related to GA/ABA metabolism and signaling pathways. Performed complex transcriptomic analysis and biological tests of WT, T-DNA insertion mutants (i.e., hy5, hfr1, and laf1), and overexpression transformants of Arabidopsis seeds (i.e., 35S:OE:HY5, 35S:OE:HYH, 35S:OE:HFR1, and 35S:OE:LAF1) highlighted that, from among all genes analyzed in this study, the $H Y 5$ coding transcription factor is most probably responsible for the regulation of expression of genes involved in GA/ABA metabolism and/or signaling pathways during BL-mediated dormancy alleviation of Arabidopsis seeds, while two other transcription factors encoded by $H Y H$ and HFR1 genes are positive regulators of seed germination.

\section{Results}

\subsection{The Effect of Blue Light on Germination of Arabidopsis Seeds Characterized by Different Depths} of Dormancy

The performed biological test of WT Arabidopsis Col-0 seeds characterized by different dormancy levels revealed that freshly harvested seeds were unable to germinate in the dark; thus, they were considered as dormant (Figure 1a,b). The germination of WT dormant seeds was promoted by the constant presence of white light $\left(180 \mu \mathrm{mol} \mathrm{m}^{-2} \mathrm{~s}^{-1}\right)$, and after $24 \mathrm{~h}$ of incubation, more than $90 \%$ of seeds were germinated (Figure 1b). Interestingly, the constant exposure of WT dormant seeds to wide range of BL intensities (from 20 up to $180 \mu \mathrm{mol} \mathrm{m} \mathrm{m}^{-2} \mathrm{~s}^{-1}$ ) stimulated germination by around $40 \%$ in compare to darkness (Figure 1a,b). Also, dry storage of freshly harvested WT dormant seeds (at room temperature, in darkness) released dormancy, allowing fast germination not only in all applied light conditions-white and BL wavelengths—but also in the dark; hence, they were recognized as nondormant (Figure 1c).

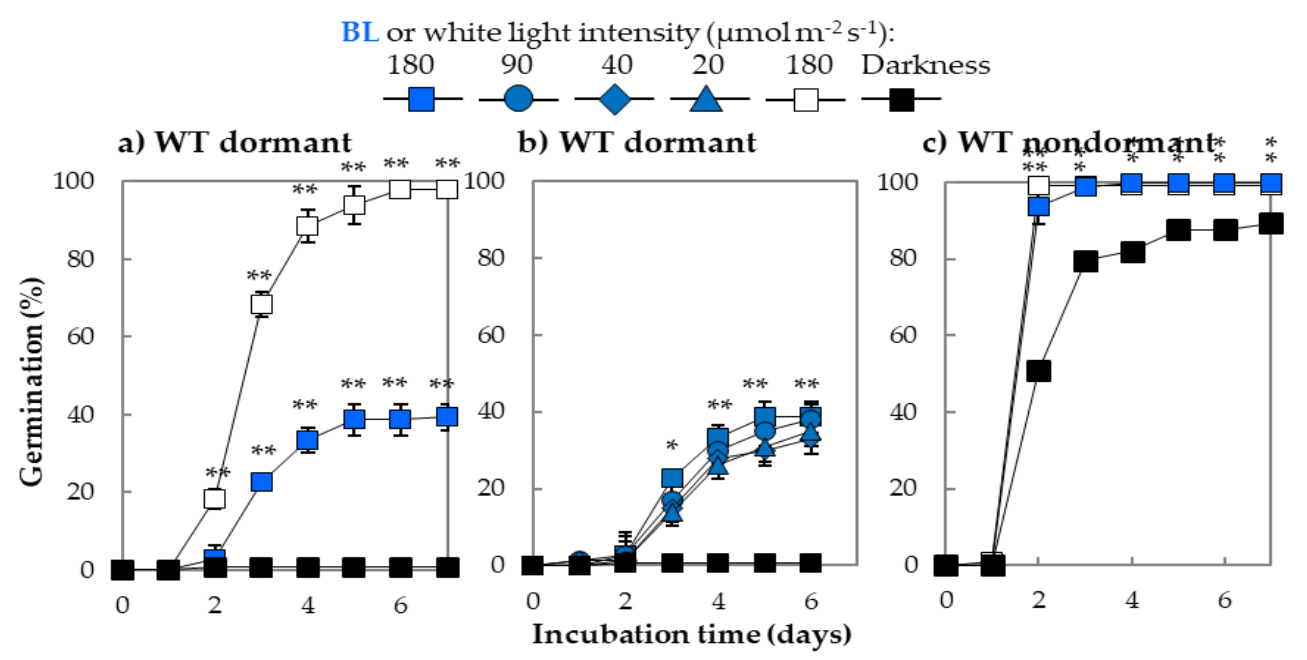

Figure 1. Characteristic of germination of wildtype (WT) Arabidopsis (Col-0) seeds: nondormant (a) and dormant $(\mathbf{b}, \mathbf{c})$ incubated on water in darkness or under blue (BL) (range of intensities from 20 to $180 \mu \mathrm{mol} \mathrm{m} \mathrm{m}^{-2} \mathrm{~s}^{-1}$ ) or white light (intensity $=180 \mu \mathrm{mol} \mathrm{m} \mathrm{m}^{-2} \mathrm{~s}^{-1}$ ) in a constant temperature of $25^{\circ} \mathrm{C}$ : Experiments were conducted in three biological and two technical replicates (100 seeds per each replicate), ${ }^{*}$ and ${ }^{* *}$ indicate the significant differences for $p \leq 0.05$ and $p \leq 0.01$ respectively. Results are presented as mean \pm SD. 
To address the question of whether stimulation of germination of WT dormant seeds requires constant BL illumination and/or shorter treatment, seeds were exposed to BL $\left(180 \mu \mathrm{mol} \mathrm{m}^{-2} \mathrm{~s}^{-1}\right)$ for different duration: 3, 6, 24, and $48 \mathrm{~h}$ (Table S1). The illumination of seeds by BL for 24 and $48 \mathrm{~h}$ resulted in similar or even stronger stimulatory effect as that of after continuous exposure to this light condition (Table S1).

Interestingly, 3 and $6 \mathrm{~h}$ of exposure of seeds to BL was not sufficient to promote germination of WT dormant seeds and results were similar to these observed in darkness. Moreover, $3 \mathrm{~h}$ illumination of WT dormant seeds by BL after $6 \mathrm{~h}$ pre-incubation in darkness had strong stimulatory effect on germination while seeds were further incubated without the presence of light-approx. $70 \%$ higher germination ratio was observed in compare to constant BL conditions. Surprisingly, the $24 \mathrm{~h}$ pre-incubation of seeds in darkness before $3 \mathrm{~h}$ illumination by BL had 22\% lower stimulatory effect on germination in compare to constant presence of BL (Table S1).

The verification of a possible interaction between BL-induced signal with GA/ABA-related pathways during germination of WT dormant Arabidopsis seeds was achieved by the biological tests of WT dormant seeds in the presence of ABA and paclobutrazol (PAC—an inhibitor of GA synthesis) (Table 1). It was observed that the treatment of WT dormant seeds by ABA and PAC solutions significantly decreased the stimulatory effect of BL on dormancy alleviation (Table 1).

Table 1. The effect of PAC $(1 \mu \mathrm{M})$ and ABA $(1 \mu \mathrm{M})$ solutions on germination rate of WT dormant Arabidopsis (Col-0) seeds incubated in darkness or under BL $\left(180 \mu \mathrm{mol} \mathrm{m}^{-2} \mathrm{~s}^{-1}\right)$ in constant temperature of $25{ }^{\circ} \mathrm{C}$ : Results were presented as \% of germinated WT dormant seeds on water or on particular treatment \pm SD after 48 and $72 \mathrm{~h}$ of incubation in constant temperature of $25^{\circ} \mathrm{C}$. Experiments were conducted in three biological and two technical replicates (100 seeds per each replicate), ${ }^{*}$ and ${ }^{* *}$ indicate the significant differences for $p \leq 0.05$ and $p \leq 0.01$ respectively.

\begin{tabular}{cccc}
\hline \multirow{2}{*}{ Constant Light Conditions } & Treatment & $\begin{array}{c}\text { Germination (\%) of WT Dormant Seeds } \\
\text { after Time of Incubation }\end{array}$ \\
\cline { 3 - 4 } & & $\mathbf{4 8 ~}$ & $\mathbf{7 2 ~} \mathbf{~ h}$ \\
\hline \multirow{2}{*}{$\mathrm{BL}$} & $\mathrm{H}_{2} \mathrm{O}$ & $14.33 \pm 0.5$ & $44.4 \pm 2.5$ \\
& $\mathrm{PAC}(1 \mu \mathrm{M})$ & $12.0 \pm 0.5$ & $15.0 \pm 1.5^{*}$ \\
& $\mathrm{ABA}(1 \mu \mathrm{M})$ & $3.0 \pm 0.33^{*}$ & $5.0 \pm 0.33^{* *}$ \\
\hline \multirow{2}{*}{ Darkness } & $\mathrm{H}_{2} \mathrm{O}$ & $0.7 \pm 0.5$ & $0.7 \pm 0.5$ \\
& $\mathrm{PAC}(1 \mu \mathrm{M})$ & $2.0 \pm 0.12$ & $2.0 \pm 0.5$ \\
& $\mathrm{ABA}(1 \mu \mathrm{M})$ & $0.0 \pm 0.0$ & $1.0 \pm 0.33$ \\
\hline
\end{tabular}

\section{2. qRT-PCR Analysis of Relative Expression of Genes Involved in Light Perception and Signaling}

\section{During Germination}

The qRT-PCR analysis preformed on samples isolated from WT dormant Arabidopsis seeds incubated under constant BL, white light, or darkness indicated that the expression of genes coding BL receptors cry1 and cry2 was very similar and did not depend on light conditions but equally increased within the duration of germination (Figure 2a). Surprisingly, the expression profile of $C R Y 3$ was different in comparison to two other homologs. In the case of $C R Y 3$, its expression increased in the presence of white light, while there is no effect observed in darkness either in the presence of BL (Figure 2a). Beside genes that are related mostly to BL perception, the expression of genes encoding R/FR light receptors, $P H Y A$ and $P H Y B$, was also investigated (Figure 2b). The PHYA expression was much lower in the presence of BL and white light in compare to darkness, while transcript levels of $P H Y B$ remained similar in all light conditions during incubation up to $48 \mathrm{~h}$ (Figure $2 \mathrm{~b}$ ). To verify if the stimulating effect of BL can be photo-reversed by the FR light, WT dormant seeds were pre-incubated for $12 \mathrm{~h}$ in the presence of BL; next, treated with FR light for $5 \mathrm{~min}$; and, then, transferred to darkness. The 5-min FR irradiation of WT dormant seeds previously incubated in the presence of BL for $12 \mathrm{~h}$ had a negative effect on germination as 2-3 times less germinated seeds were observed in compare to 
seeds incubated for $12 \mathrm{~h}$ or continuously in the presence of BL (Figure 2c).The possible involvement of cry and phy photoreceptors in the mechanism of BL-mediated dormancy alleviation was attested in germination assay of dormant seeds: WT and mutants of genes encoding particular cry and phy, such as WT Col-0, phyA, phyB, cry1, and cry3 (in Col-0 background) and WT Ler-0 and cry1cry2 (Ler-0 ecotype) (Figure 2d).

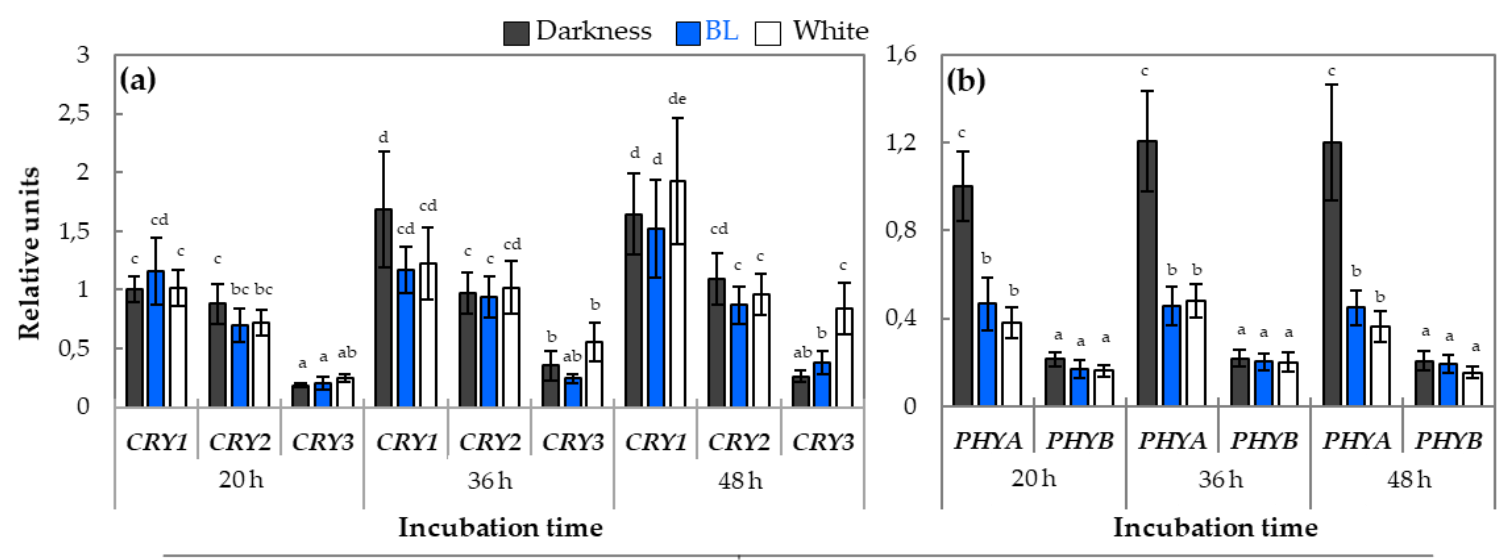

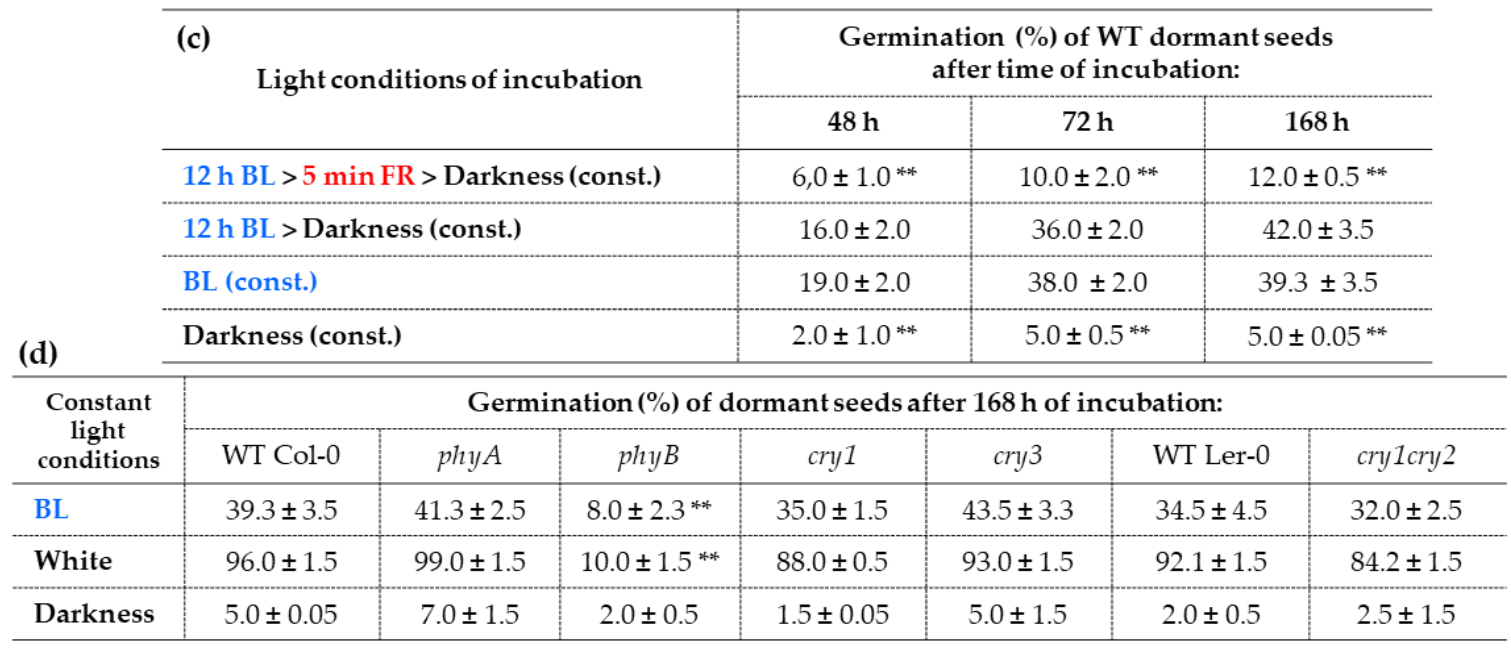

Figure 2. The relative expressions of genes encoding photoreceptors $C R Y 1, C R Y 2$, and $C R Y 3$ (a) and $P H Y A$ and $P H Y B(\mathbf{b})$ in samples isolated from WT dormant Arabidopsis (Col-0) seeds incubated on water for 20,36, and $48 \mathrm{~h}$ in different light conditions (BL and white light of intensity $=180 \mu \mathrm{mol} \mathrm{m}^{-2}$ $\mathrm{s}^{-1}$, darkness) at a temperature of $25^{\circ} \mathrm{C}$ : The transcript level was normalized to reference genes ( $A C T 7$, $A P C 2$, and $H B T$ ) and to the internal control, which was the expression value of $C R Y 1$ (Figure 2a) or PHYA (Figure $2 \mathrm{~b}$ ) obtained in darkness after $20 \mathrm{~h}$ of incubation. Three biological and two technical replicates were performed. The bars show the relative units $\pm \mathrm{SD}$. The effect of far red (FR) on the regulation of WT dormant Arabidopsis (Col-0) seeds germination by BL light (c). Seeds were incubated on water in constant temperature of $25^{\circ} \mathrm{C}$ at various light conditions. The results are presented as germination $\%$ of WT dormant Arabidopsis (Col-0) seeds after 48, 72, and $168 \mathrm{~h}$ of incubation. For BL-dependent germination assay, seeds were exposed to $5 \mathrm{~min}$ of FR light irradiation (intensity $=60 \mu \mathrm{mol} \mathrm{m}^{-2} \mathrm{~s}^{-1}$ ) after $12 \mathrm{~h}$ of pre-imbibition in the presence of BL (intensity $=180 \mu \mathrm{mol} \mathrm{m}^{-2} \mathrm{~s}^{-1}$ ). (d) The germination $\%$ of WT dormant seeds (in Col-0 background: WT Col-0, phyA, phyB, cry1, and cry3; in Ler-0 ecotype: WT Ler- 0 and cry1cry2) after $168 \mathrm{~h}$ of incubation on water in the presence of constant BL and white light (intensity $=180 \mu \mathrm{mol} \mathrm{m}^{-2} \mathrm{~s}^{-1}$ ) or in darkness at temperature of $25^{\circ} \mathrm{C}$. Germination assays were performed in three biological and two technical replicates (100 seeds per each replicate). Results are presented as mean $\pm \mathrm{SD}),{ }^{* *}$ indicates the significant differences for $p \leq 0.05$ and $p \leq 0.01$ respectively.

All tested seeds did not germinate in darkness. The dormancy was alleviated by the constant presence of BL or white light $\left(180 \mu \mathrm{mol} \mathrm{m}^{-2} \mathrm{~s}^{-1}\right)$ in all tested types of seeds except phyB. After $168 \mathrm{~h}$ of 
incubation, approx. $40 \%$ and $90 \%$ of dormant seeds WT Col-0, phyA, cry 1 , and cry3, and WT Ler- 0 and cry1cry 2 germinated respectively on BL and white light, while in the case of $p h y B$, just $8-10 \%$ seeds germinated in these conditions (Figure 2d).

Due to the fact that in signaling pathway of BL are involved different regulatory proteins (i.e., CIB, PHR2 (PHOTOLYASE/BLUE LIGHT RECEPTOR 2), PP7 (SERINE/THREONINE PHOSPHATASE 7), SUB1 (ARABIDOPSIS CALCIUM-BINDING PROTEIN 1), and COP1), the expression profiles of genes coding them were investigated in samples obtained from germinating WT dormant seeds. Obtained results showed correlation between light conditions in which WT dormant seeds were incubated and expression of CIB1 and CIB5 genes (Figure 3a,b). In darkness, expressions of $C I B 1$ and $C I B 5$ were lower in comparison to that which was much higher in BL and white light conditions. Moreover, the presence of BL and white light increased CIB1 and CIB5 expression during incubation, while in darkness, the opposite effect was observed. In the case of PHR2, after $20 \mathrm{~h}$ of incubation of WT dormant seeds, its expression was at a similar level in BL and darkness and a bit higher in the presence of white light. However, within the duration of incubation, the expression of PHR2 decreased in darkness, was unchanged in the presence of $\mathrm{BL}$, and almost doubled in white light (Figure 3c). The PP7 gene shows similar expression levels in all light conditions after 20 and $36 \mathrm{~h}$ of incubation (Figure 3d). At later time point of incubation (48 h), expression of PP7 increased in all light conditions, with a tendency to be higher in samples incubated in white light. The expression of SUB1 after $20 \mathrm{~h}$ of incubation was similar in samples isolated from all light conditions (Figure 3e). Within the duration of seed incubation, the level of SUB1 transcripts in darkness slightly decreased but increased in the presence of BL and white light. In the case of COP1 gene, its expression in darkness was lower in comparison to light conditions and did not changed after $20 \mathrm{~h}$ of germination. Interestingly, the presence of light, especially the BL wavelength, stimulated COP1 expression after 36 and $48 \mathrm{~h}$ of incubation (Figure 3f).

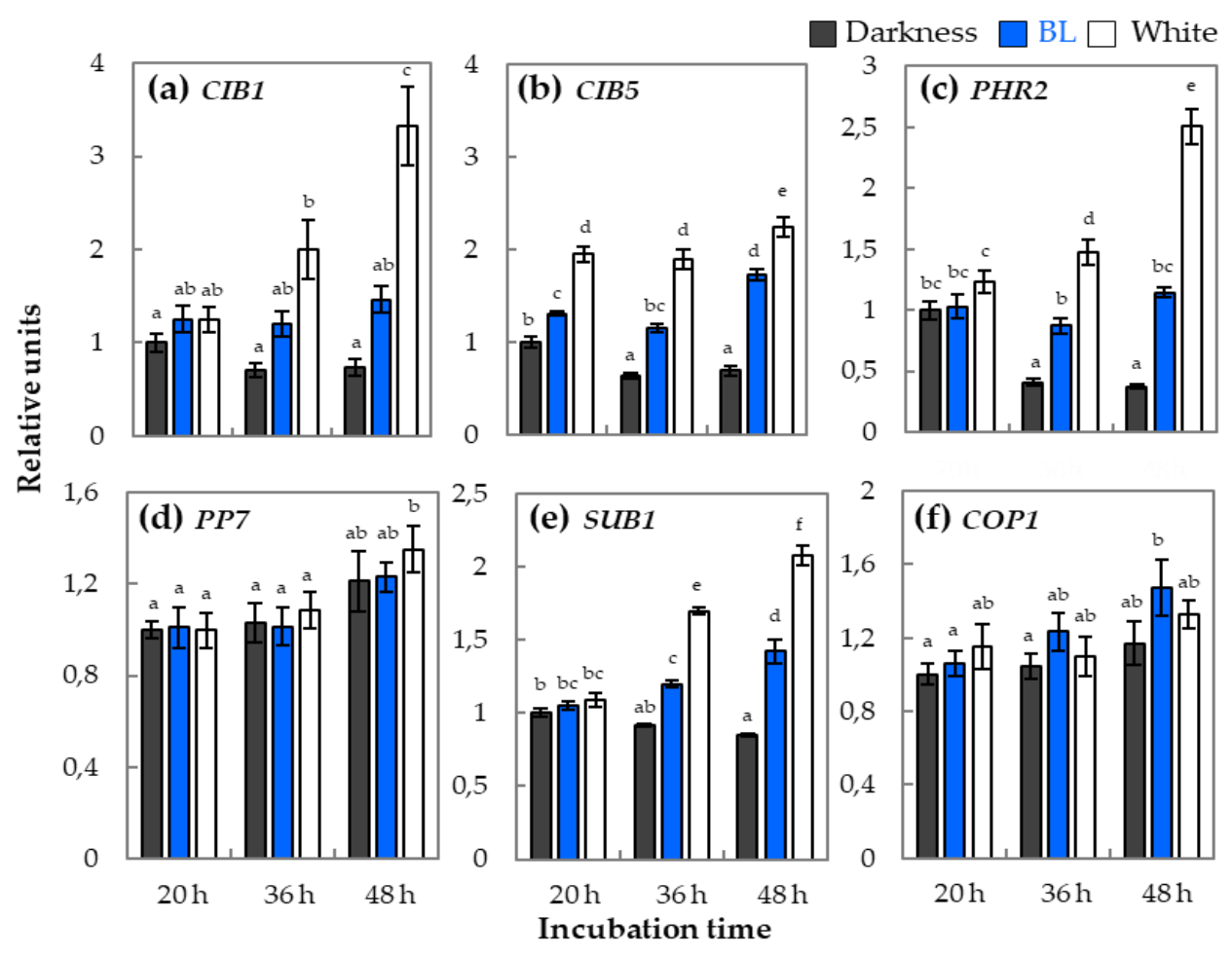

Figure 3. The analysis of relative expression of genes encoding regulatory proteins involved in light signaling, such as CIB1 (a), CIB5 (b), PHR2 (c), PP7 (d), SUB1 (e), and COP1 (f), in WT dormant Arabidopsis (Col-0) seeds incubated for 20,36, and $48 \mathrm{~h}$ on water in different light conditions (BL and white light of intensity $=180 \mu \mathrm{mol} \mathrm{m} \mathrm{m}^{-2}$, darkness) at temperature of $25^{\circ} \mathrm{C}$ : The transcript level was 
normalized to reference genes (ACT7, APC2, and HBT) and to the internal control, which was the expression value of each particular gene observed in seeds incubated for $20 \mathrm{~h}$ in darkness. Three biological and two technical replicates were performed. The bars show the relative units \pm SD, letters a-f indicate homogeneous groups for $p \leq 0.05$.

The expression patterns of light-related transcription factors, such as HY5, HYH, HFR1, and LAF1, were also investigated. The expression of all these genes was strongly correlated with light conditions (Figure 4). The results of qRT-PCR analysis indicated that it was mostly the BL component of the light spectrum that stimulated not only HY5 and HYH but also HFR1 expression (Figure 4a-c). The expressions of all these 3 genes were at drastically low levels in seeds incubated in darkness. In the case of $L A F 1$, the pattern was much different, as the highest expression was observed in seeds incubated in darkness, while the presence of white light kept it at rather low level (Figure 4d). The presence of BL had also a reducing effect on LAF1 expression, but the result was not so strong as the one caused by white light.

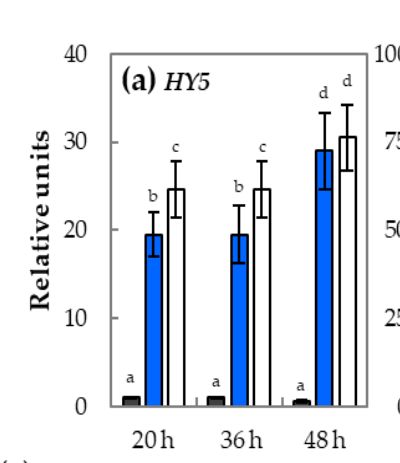

(e)

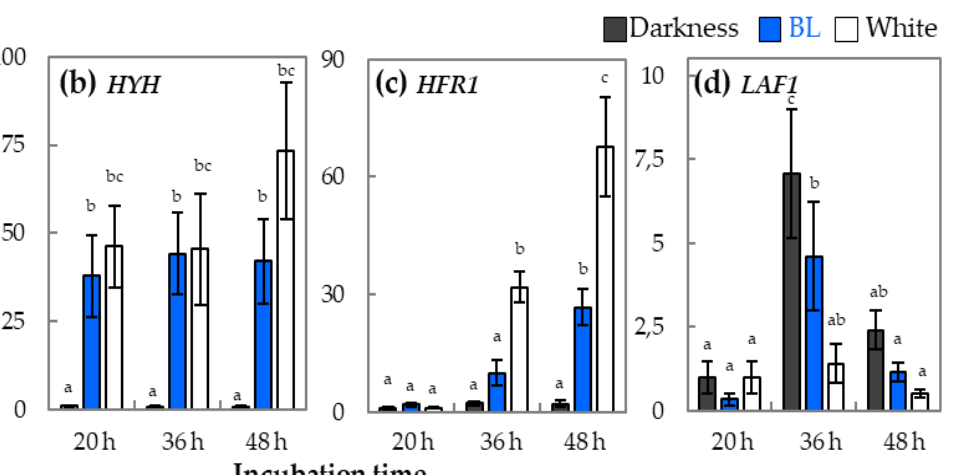

\begin{tabular}{l|c|c|c|c|c|c|c|c}
\hline \multirow{2}{*}{$\begin{array}{c}\text { Constant } \\
\text { light } \\
\text { conditions }\end{array}$} & \multicolumn{7}{|c|}{ Germination (\%) of dormant seeds after 168h of incubation: } \\
\cline { 2 - 9 } & WT Col-0 & $35 S: O E: H Y H$ & $35 S: O E: H F R 1$ & $35 S: O E: H Y 5$ & $35 S: O E: L A F 1$ & $h f r 1$ & hy5 & laf1 \\
\hline BL & $39.3 \pm 3.5$ & $38.3 \pm 2.5$ & $37.0 \pm 2.3$ & $1.0 \pm 1.0 * *$ & $31.5 \pm 2.5$ & $35.0 \pm 3.5$ & $59.0 \pm 1.5^{*}$ & $40.0 \pm 2.5$ \\
\hline White & $96.0 \pm 1.5$ & $94.0 \pm 0.5$ & $92.0 \pm 0.5$ & $8.0 \pm 0.5^{* *}$ & $93.0 \pm 1.5$ & $97.0 \pm 0.5$ & $92.0 \pm 2.0$ & $95.0 \pm 3.0$ \\
\hline Darkness & $5.0 \pm 0.05$ & $7.0 \pm 1.5$ & $2.0 \pm 0.5$ & $1.5 \pm 0.5$ & $4.0 \pm 1.5$ & $6.0 \pm 0.5$ & $4.0 \pm 1.0$ & $8.0 \pm 0.05$ \\
\hline
\end{tabular}

Figure 4. The analysis of the relative expressions of genes encoding transcription factors related to light signaling, such as HY5 (a), HYH (b), HFR1 (c), and LAF1 (d), in samples isolated from WT dormant Arabidopsis (Col-0) seeds incubated on water for 20,36, and $48 \mathrm{~h}$ in different light conditions (BL and white light of intensity $=180 \mu \mathrm{mol} \mathrm{m} \mathrm{m}^{-2} \mathrm{~s}^{-1}$, darkness) at temperature of $25^{\circ} \mathrm{C}$ : The transcript level was normalized to reference genes $(A C T 7, A P C 2$, and HBT) and to the internal control, which was the expression value of each particular gene observed in seeds incubated for $20 \mathrm{~h}$ in darkness. Three biological and two technical replicates were performed. The bars show the relative units \pm SD, letters a-d indicate homogeneous groups for $p \leq 0.05$. The germination $\%$ of dormant Arabidopsis seeds (in Col-0 background: WT Col-0, 35S:OE:HYH, 35S:OE:HFR1, 35S:OE:HY5, 35S:OE:LAF1, hfr1, hy5, and laf1) after $168 \mathrm{~h}$ of incubation on water in the presence of constant BL and white light (intensity = $180 \mu \mathrm{mol} \mathrm{m}{ }^{-2} \mathrm{~s}^{-1}$ ) or in darkness at temperature of $25^{\circ} \mathrm{C}(\mathbf{e})$. Experiments were conducted in three biological and two technical replicates (100 seeds per each replicate). Results are presented as mean \pm $\mathrm{SD}, *$ and $* *$ indicate the significant differences for $p \leq 0.05$ and $p \leq 0.01$ respectively.

The possible involvement of genes encoding light-related transcription factors in the mechanism of BL-mediated dormancy alleviation was verified also in germination assays of dormant Arabidopsis Col-0 seeds: WT and overexpression transformants, such as 35S:OE:HY5, 35S:OE:HYH, 35S:OE:HFR1, and 35S:OE:LAF1, and T-DNA insertion mutants, i.e., hfr1, hy5, and laf1 (Figure 4e). All tested seeds did not germinate in darkness. The dormancy was alleviated by the constant presence of BL or white light $\left(180 \mu \mathrm{mol} \mathrm{m} \mathrm{m}^{-2} \mathrm{~s}^{-1}\right)$ in all tested types of seeds except 35S:OE:HY5. After $168 \mathrm{~h}$ of incubation, 
approx. $30-40 \%$ and $90 \%$ of seeds WT Col-0, 35S:OE:HYH, 35S:OE:HFR1, and 35S:OE:LAF1 were germinated respectively on BL and white light, while in the case of 35S:OE:HY5, just 1-8\% seeds germinated in these conditions (Figure 4e). In the case of T-DNA insertion mutants, the BL effect on dormancy alleviation was significantly stronger in the case of seeds of hy5 mutant (Figure 4e).

\subsection{The Analysis of Expression Profiles of Genes Involved in GA Metabolism and Signaling in Light-Dependent} Germination of Dormant Seeds

The qRT-PCR analysis of relative expression of genes playing a role in GA metabolism and signaling was performed in WT dormant seeds incubated for 20, 36, and $48 \mathrm{~h}$ in different light conditions (darkness, BL, and white light) (Figures 5-7).

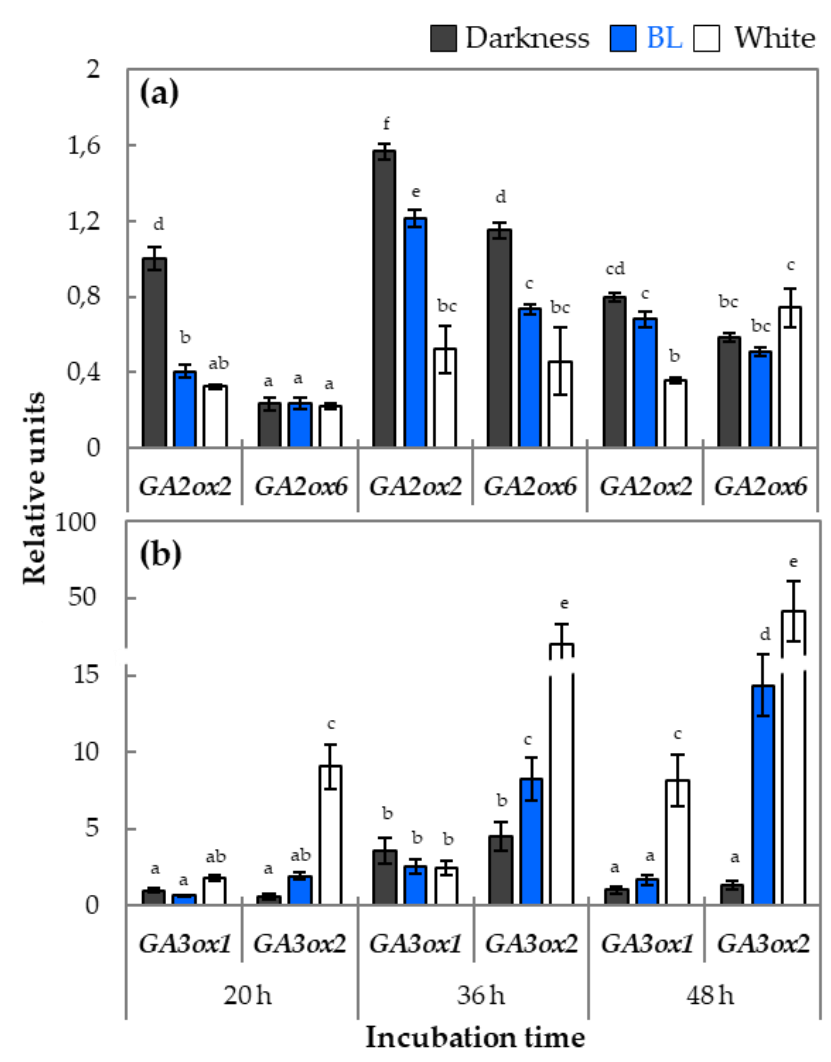

Figure 5. The relative expressions of genes encoding enzymes involved in GA metabolism: degradation-GA2ox2 and GA2ox6 (a) —and biosynthesis-GA3ox1 and GA3ox2 (b), in samples isolated from WT dormant Arabidopsis (Col-0) seeds incubated on water for 20,36, and $48 \mathrm{~h}$ in different light conditions (BL and white light of intensity $=180 \mu \mathrm{mol} \mathrm{m} \mathrm{m}^{-2} \mathrm{~s}^{-1}$, darkness) at temperature of $25^{\circ} \mathrm{C}$. The transcript level was normalized to reference genes $(A C T 7, A P C 2$, and $H B T)$ and to the internal control, which was the expression value of GA2ox2 (Figure 5a) or GA3ox1 (Figure 5b) obtained in darkness after $20 \mathrm{~h}$ of incubation. Three biological and two technical replicates were performed. The bars show the relative units $\pm \mathrm{SD}$, letters a-f indicate homogeneous groups for $p \leq 0.05$.

The effect of light conditions on the expression of genes involved in GA degradation was investigated on the examples of two representatives from GA2ox group, such as GA2ox2 and GA2ox6 (Figure 5a). Interestingly, the expression profiles of both genes indicated that, in the presence of BL and white light, their transcript levels were lower in comparison to darkness. The differences in expression of GA2ox2 was much higher especially after $20 \mathrm{~h}$ and $36 \mathrm{~h}$ and, in the case of GA2ox6, after $36 \mathrm{~h}$ (Figure 5a). Among the genes involved in GA biosynthesis, GA3ox1, GA3ox2, and KAO2 were examined (Figure 5b, Figure S1). The expression profiles of both GA3ox genes showed correlation between light conditions of incubation and the transcript level in the case of GA3ox2, with a tendency 
that, in darkness, expression of GA3ox2 was lower than in the presence of BL and white light (Figure 5b). The analysis of the $K A O 2$ relative expression indicated that its transcript level was higher in seeds incubated under white light for $20 \mathrm{~h}$ in comparison to BL and darkness and was equal in all light conditions after $36 \mathrm{~h}$, while at the late time point of germination $(48 \mathrm{~h})$, the lack of light resulted in doubling its expression in comparison to the presence of BL or white light (Figure S1).

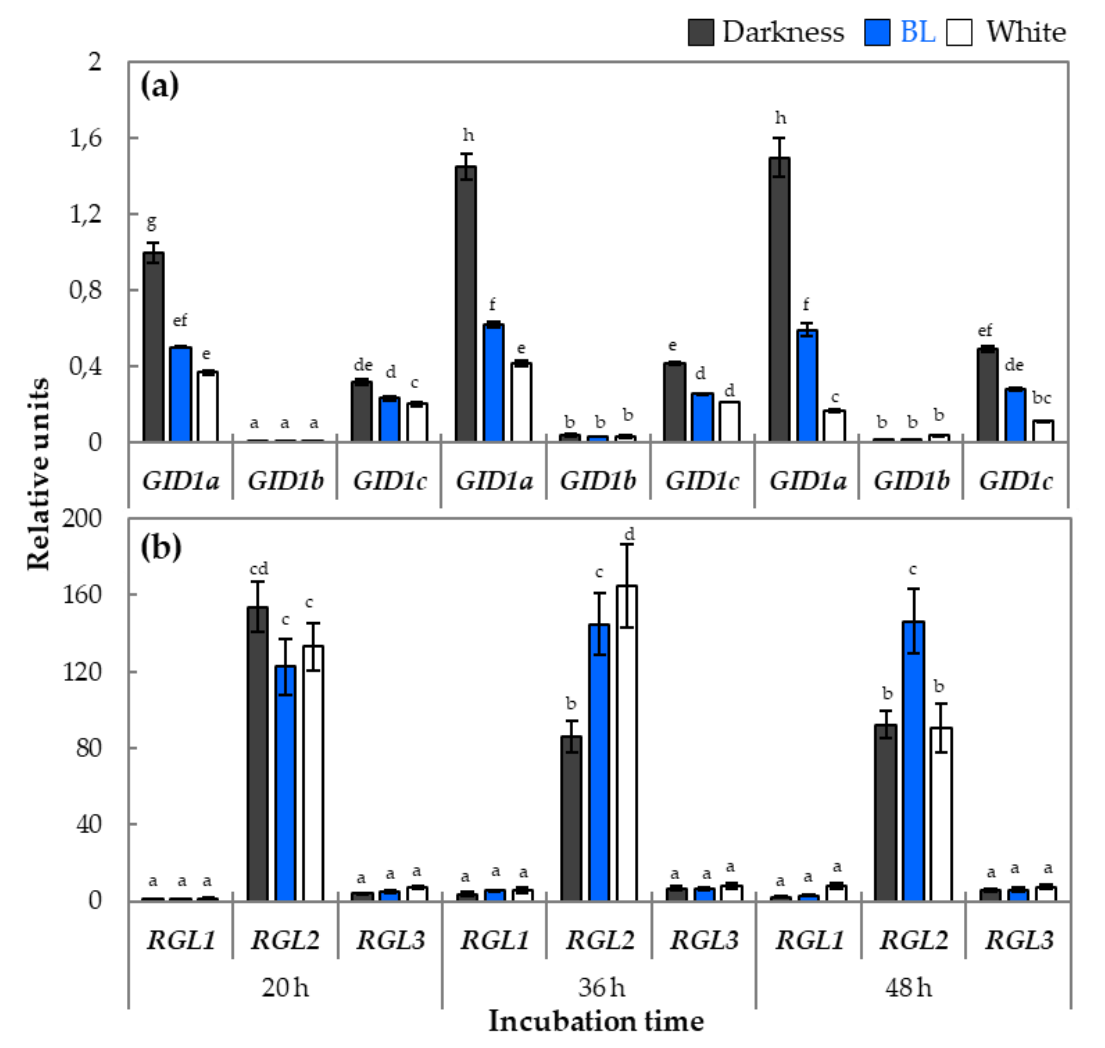

\begin{tabular}{ccccc}
\hline $\begin{array}{c}\text { (c) } \begin{array}{c}\text { Light } \\
\text { conditions of } \\
\text { incubation }\end{array} \\
\text { Darkness }\end{array}$ & $\begin{array}{c}\text { Effect of GA treatment on genes expression } \\
\left.\text { (\% of relative transcripts level in seeds imbibed on } \mathrm{H}_{2} \mathrm{O}\right)\end{array}$ \\
\hline White & $77.3 \pm 2.7^{*}$ & $12.3 \pm 1.1^{* *}$ & $59.3 \pm 1.3^{*}$ & $165.7 \pm 8.6^{*}$ \\
\hline White & $112.1 \pm 2.7^{*}$ & $32.0 \pm 1.2^{* *}$ & $79.7 \pm 2.4$ & $136.8 \pm 4.6^{* *}$ \\
\hline
\end{tabular}

Figure 6. The relative expressions of genes encoding proteins involved in GA signaling, such as GID1a, GID1b, and GID1c (a) and RGL1, RGL2, and RGL3 (b), in samples isolated from WT dormant Arabidopsis (Col-0) seeds incubated on water for 20,36, and $48 \mathrm{~h}$ in different light conditions (BL and white light of intensity $=180 \mu \mathrm{mol} \mathrm{m} \mathrm{m}^{-2} \mathrm{~s}^{-1}$, darkness) at temperature of $25^{\circ} \mathrm{C}$ : The transcript level was normalized to reference genes $(A C T 7, A P C 2$, and $H B T)$ and to the internal control, which was the expression value of GID1a (Figure 6a) or RGL1 (Figure 6b) obtained in darkness after $20 \mathrm{~h}$ of incubation. Three biological and two technical replicates were performed. The bars show the relative units $\pm S D$, letters a-h indicate homogeneous groups for $\mathrm{p} \leq 0.05$. The effect of GA $(50 \mu \mathrm{M})$ treatment on GID1a, GID1b, GID1c, and RGL2 expression in samples isolated from WT dormant Arabidopsis seeds incubated in darkness or white light for $20 \mathrm{~h}$ by qRT-PCR method (c). Results are expressed as $\%$ of relative transcript levels presented in seeds imbibed on water $\pm \mathrm{SD},{ }^{*}$ and ${ }^{* *}$ indicate the significant differences for $p \leq 0.05$ and $p \leq 0.01$ respectively.

To assess in more details the impact of BL on the transcript abundance of genes related to GA signaling, the characteristic of expression profiles of genes encoding GA receptors, such as GID1a, GID1b, and GID1c, as well as three genes encoding DELLA factors RGL1, RGL2, and RGL3 were 
performed in samples analogous as in the case of genes involved to light signaling and GA metabolism (Figure 6). The expression profile of GID1a and GID1c under white and BL was significantly lower than in darkness (Figure 6a). Interestingly, the expression profile of GID1b was much lower than that of the two other GID1 genes.

The further analysis of the expression of three RGL genes indicated that the highest transcript level had RGL2 (Figure 6b). Moreover, the expression of RGL2 gene after $20 \mathrm{~h}$ of incubation was at a similar level in samples obtained from all light conditions, while after $36 \mathrm{~h}$, it decreased in darkness and was lower by approx. $40 \%$ in comparison to BL and white light conditions. At the later investigated time point of germination ( $48 \mathrm{~h}$ ), the transcript level of RGL2 in samples incubated on white light decreased and obtained similar levels as the one observed in darkness, while it was still high in samples exposed to BL. The expressions of RGL1 and RGL3 did not show significant differences in all applied light conditions (Figure 6 b).

To examine in more details the potential interaction between light and GA signaling pathways, additional qRT-PCR analyses of RGL2 and all three GID1 genes expressions were performed in samples obtained from germinating WT dormant seeds treated with GA solution (Figure 6c). It was observed that exogenous GA decreased relative GID1b and GID1c expression in darkness and in the presence of white light. Interestingly, the expression of GID1a decreased in GA-treated seeds incubated in darkness but increased in white light. In the case of RGL2, the application of GA resulted in an increase of RGL2 expression for about 65 and 37\%, respectively, in darkness and in white light (Figure 6c).

(a)

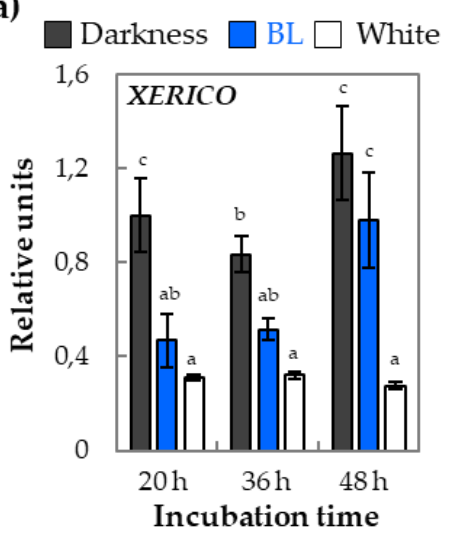

(b)
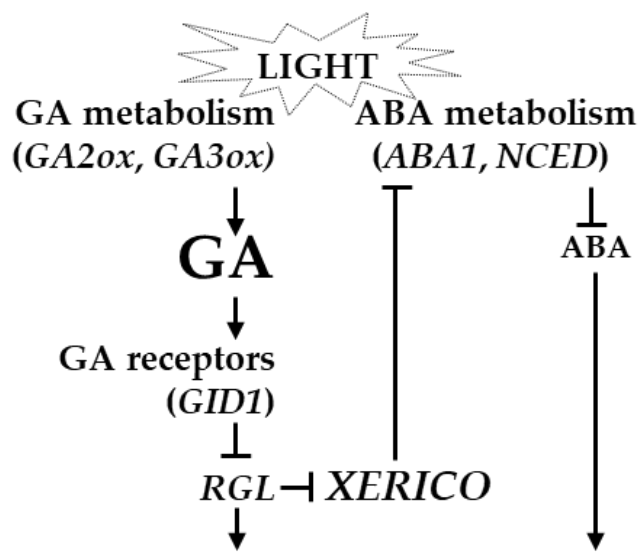

Dormancy alleviation and stimulation of germination

Figure 7. The relative expression of the XERICO gene in samples isolated from WT dormant Arabidopsis (Col-0) seeds incubated on water for 20, 36, and $48 \mathrm{~h}$ in different light conditions (BL and white light of intensity $=180 \mu \mathrm{mol} \mathrm{m} \mathrm{s}^{-1}$, darkness $)$ at temperature of $25^{\circ} \mathrm{C}(\mathbf{a})$ : The transcript level was normalized to reference genes $(A C T 7, A P C 2$, and $H B T)$ and to the internal control, which was the expression value of XERICO gene obtained in darkness after $20 \mathrm{~h}$ of incubation. Three biological and two technical replicates were performed. The bars show the relative units $\pm \mathrm{SD}$, letters a-c indicate homogeneous groups for $p \leq 0.05$. (b) The schematic presentation of the influence of light on GA and ABA metabolism and transduction of signal induced by these phytohormones during dormancy alleviation of imbibed seed: Light releases dormancy by modulation of expression of genes involved in GA and ABA metabolism, leading to changes in GA and ABA concentration and further in GA-dependent signal transduction via GID1, RGL, and XERICO genes.

The potential interaction between GA and ABA metabolism and signaling pathways in lightdependent germination of WT dormant Arabidopsis seeds was verified by the qRT-PCR analysis of the transcript level of the XERICO gene (Figure 7). The obtained results indicated that, in germinating WT dormant seeds, the expression of this gene is negatively regulated by the presence of BL and white light. 
2.4. The Expression Patterns of Genes Involved in ABA Metabolism and Signaling in Light-Dependent Germination of Dormant Seeds

For the better understanding of the mechanism of $\mathrm{BL}$ action during germination of WT dormant seeds, the expression patterns of genes involved in ABA biosynthesis, such as ABA1, NCED6, and NCED9 (Figure 8a-c), and in degradation, such as CYP707A2 (Figure 8d), were investigated. The transcript levels of $A B A 1, N C E D 6$, and NCED9 genes depend on the light conditions as they were the highest in seeds incubated in darkness and much lower in the presence of BL and white light. For the ABA degradation gene-CYP707A2-a clear pattern according to different light conditions was not observed. The relatively high expression of CYP707A2 gradually decreased within the duration of incubation. After $48 \mathrm{~h}$ of imbibition CYP707A2 expression was significantly higher in darkness in compare to BL and white light (Figure 8d).

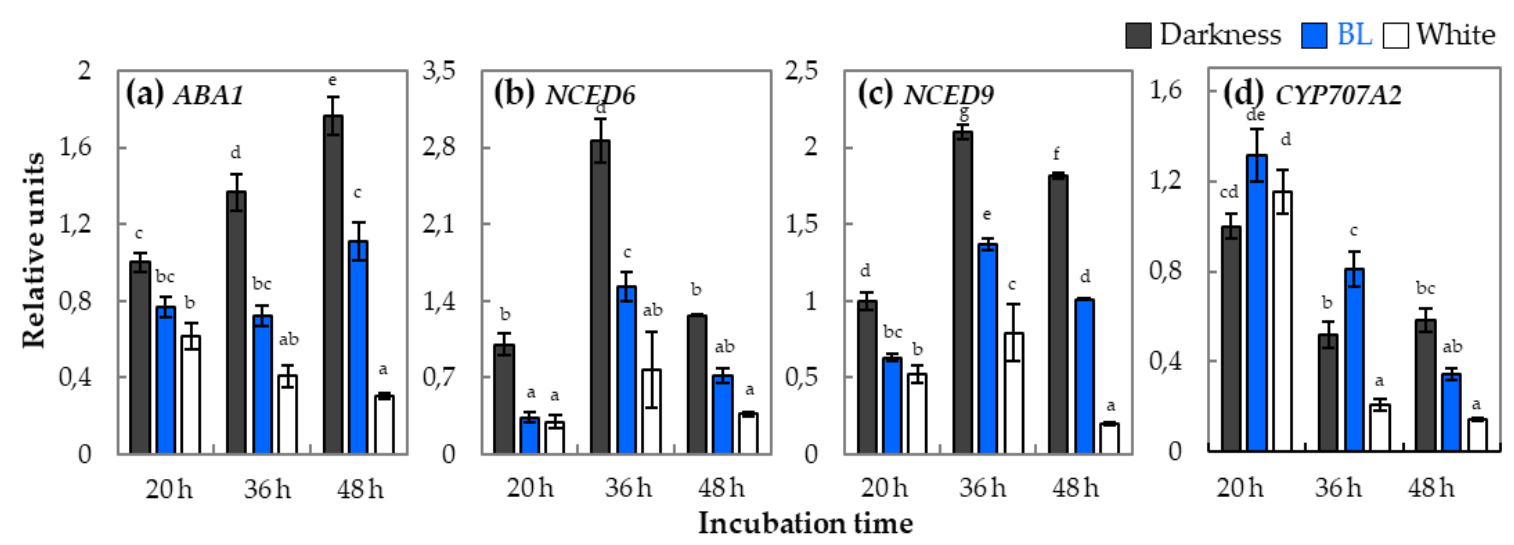

Figure 8. The analysis of relative expressions of genes encoding enzymes involved in ABA metabolism, such as ABA1 (a), NCED6 (b), NCED9 (c), and CYP707A2 (d), in samples isolated from WT dormant Arabidopsis (Col-0) seeds incubated on water for 20,36, and $48 \mathrm{~h}$ in different light conditions (BL and white light of intensity $=180 \mu \mathrm{mol} \mathrm{m} \mathrm{m}^{-2} \mathrm{~s}^{-1}$, darkness) at temperature of $25^{\circ} \mathrm{C}$ : The transcript level was normalized to reference genes $(A C T 7, A P C 2$, and $H B T)$ and to the internal control, which was the expression value of each particular gene observed in seeds incubated for $20 \mathrm{~h}$ in darkness. Three biological and two technical replicates were performed. The bars show the relative units \pm SD, letters a-g indicate homogeneous groups for $p \leq 0.05$.

To verify the impact of $\mathrm{BL}$ on the transcripts abundance of genes related to ABA signaling, the characteristic of expression profiles of $A B I$ and $H A I$ genes encoding, respectively, $\mathrm{ABI}$ transcription factors and protein phosphatases type $2 \mathrm{C}$ was performed (Figure 9).

The obtained results indicated that the ABI3, ABI5, HAI1, HAI2, and HAI3 genes had significantly higher relative expressions in samples obtained from WT dormant seeds germinated in darkness than those incubated under BL and/or white light (Figure 9). Moreover, these differences increased within the duration of incubation. Interestingly, in the case of the ABI4 gene, the reverses trend was observed, as the presence of BL and/or white light was positively correlated with its transcript level (Figure 9a). 


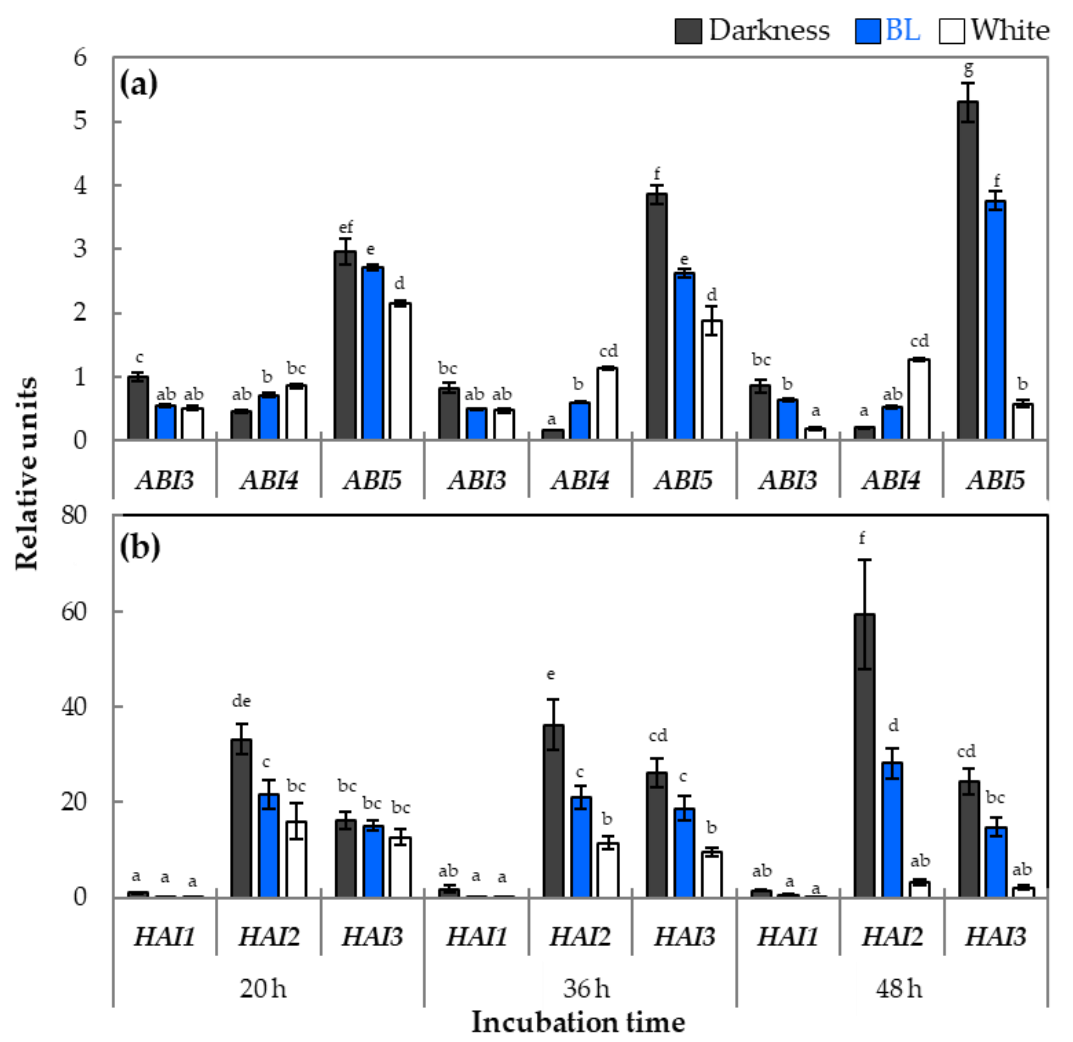

Figure 9. The relative expressions of genes encoding proteins involved in ABA signaling, such as $A B I 3$, $A B I 4$, and $A B I 5$ (a) and HAI1, HAI2, and HAI3 (b), in samples isolated from WT dormant Arabidopsis (Col-0) seeds incubated on water for 20,36, and $48 \mathrm{~h}$ in different light conditions (BL and white light of intensity $=180 \mu \mathrm{mol} \mathrm{m} \mathrm{m}^{-2}$, darkness) at temperature of $25^{\circ} \mathrm{C}$ : The transcript level was normalized to reference genes ( $A C T 7, A P C 2$, and $H B T)$ and to the internal control, which was the expression value of $A B I 3$ (Figure 9a) or HAI1 (Figure 9b) obtained in darkness after $20 \mathrm{~h}$ of incubation. Three biological and two technical replicates were performed. The bars show the relative units \pm SD, letters a-g indicate homogeneous groups for $p \leq 0.05$.

\section{Discussion}

\subsection{Blue Light Alleviates Dormancy and Stimulates Germination of Arabidopsis Seeds}

The scientific literature provides us relatively much information about the role of R/FR light in seed germination of dicot plants, while the role of blue light (BL) is mainly discussed in the context of seed biology of monocot plants [15]. Studies conducted on mutants of Arabidopsis lacking active forms of R/FR light receptors phy confirmed that these proteins are responsible for the perception of light inducing seed germination and that R/FR light plays an important role in this process [30]. It is also known that, for monocot plants, such as barley (Hordeum vulgare L.) and wheat (Triticum aestivum L.), BL light received by cry inhibits germination of freshly harvested seeds of these species [28,31,32]. Surprisingly, the role and the mechanism of action of BL in seed biology of dicot plants including Arabidopsis is still very poorly understood. In this particular study, it was found that dormancy of freshly harvested Arabidopsis seeds which were unable to germinate in darkness (at $25^{\circ} \mathrm{C}$ ) can be released: 1) during dry after-ripening for at least 8 weeks or 2) by continuous or even short treatment of imbibed WT dormant seeds by BL and/or white light (Figure 1, Table S1). Worth noticing is that the effect of dormancy alleviation and germination stimulation mediated by BL and/or white light depends on the depth of dormancy. Further biological tests unrevealed also that incubation of WT dormant seeds in the presence of BL at range of intensities from $20 \mathrm{up}$ to $180 \mu \mathrm{mol} \mathrm{m}^{-2} \mathrm{~s}^{-1}$ resulted in a similar stimulatory effect (Figure 1b). This result showed that both relatively low and high BL light 
intensity values stimulate germination; thus, in the natural environment its effect could be noticeable in fluctuating conditions of irradiance caused, i.e., by the presence of clouds and/or air pollutants. Based on these results, it is concluded that dormancy alleviation and stimulation of germination by BL most probably is a low fluence response (LFR) dependent on phyB. These findings are supported by earlier published results, where it was demonstrated that, during photoinduced germination of Arabidopsis seeds, phyA opposed to phyB mediates very low fluence response (VLFR) [7,17]. In this particular study, it was also demonstrated that pre-incubation of WT dormant Arabidopsis seeds in darkness for $24 \mathrm{~h}$ before $3 \mathrm{~h}$ illumination of them by BL decreased its stimulating effect, while the shorter pre-treatment in darkness for $6 \mathrm{~h}$ had an opposite effect (Suppl. Table 1). Interestingly, to break dormancy, it was required to apply BL for at least $24 \mathrm{~h}$ starting from the beginning of imbibition process or at a min. of $3 \mathrm{~h}$ of BL illumination but on seeds which were previously pre-incubated for 6-24 h in darkness (Table S1). These observations bring us to the conclusion that not only the duration of seed illumination by BL but also, more importantly, at which step of seed germination the BL is applied are crucial for the dormancy release. It seems that the sensitivity of WT dormant seeds to BL stimulus is changing within the duration of incubation, with the highest sensitivity occurring between 6 and $9 \mathrm{~h}$ of germination. Following this conclusion, it can be suggested that pre-imbibition of WT dormant seeds in the dark (especially between 6 and $24 \mathrm{~h}$ ) do not allow for the removal of negative regulators and/or synthesis of stimulators of germination, leading then to inhibition of this process even in the presence of BL applied after $24 \mathrm{~h}$ of imbibition.

\subsection{The phy Perceive Blue Light in Germinating Dormant Arabidopsis Seeds}

The role of BL in germination of dicot seeds and its mechanism of action have not been yet well elucidated. It is still unclear which particular genes are involved in the BL signaling pathway and what target genes are responsible for regulation of germination of WT dormant Arabidopsis seeds. There are evidences that the perception of BL occurs mainly through cry, but it can also take place through proteins from phy family $[33,34]$. Therefore, to verify which of these photoreceptors might be involved in the perception of BL in germinating seeds, the qRT-PCR analysis of genes, such as CRY1, $C R Y 2, C R Y 3, P H Y A$, and $P H Y B$ encoding these regulatory proteins, were performed. It was shown that CRY1 and CRY2 expression in WT dormant Arabidopsis seeds incubated in all tested light conditions was at a relatively similar level and did not depend on light conditions (Figure 2a). In the case of CRY3 gene, its expression in germinating WT dormant seeds was much lower in compare to two other homologs and, furthermore, was positively correlated with the presence of white light (Figure 2a). In the later stages of germination (after $48 \mathrm{~h}$ ), the relatively small stimulatory effect of BL on CRY3 expression was also observed. The expression profile of $C R Y 3$ suggests that this gene may play an important role in seed germination but that its biological function seems to be different from CRY1 and CRY2. The cry3 protein, unlike cry1 and cry2, has a different type of photolyase activity and has the ability to bind to ssDNA (single-stranded DNA) and RNA and to repair some types of damages caused, e.g., by UV radiation [14,35]. In addition, unlike other cry, it is localized in chloroplasts and mitochondria; thus taking into account the biochemical activity of cry3, it may mean that it is involved in the protection of organellar genomes $[14,36]$. Therefore, it can be possible that during activation of the metabolism in germinating seeds, cry3 may be involved in protection of mitochondrial DNA against oxidative damages.

Considering the role of phy receptors in Arabidopsis seeds germination controlled by BL, it was discovered that only PHYA expression significantly decreased under BL and white light while PHYB was at a relatively low, stable level in each light condition (Figure 2b). This is in agreement with earlier research performed on Arabidopsis seedlings, which showed that PHYA expression was strongly inhibited by white light, and a smaller effect of light was observed on $P H Y B \quad[7,37,38]$. To decipher the potential correlation between cry (BL)- and phy (R/FR)- related pathways in light-mediated dormancy alleviation, the effect of FR on the stimulation of WT dormant Arabidopsis seeds germination by BL was verified by biological assay (Figure 2c). It was discovered that the application of FR after BL 
illumination during germination of dormant WT seeds significantly reduced the stimulatory effect of BL on this process. Moreover, the results of germination assay of dormant WT and mutants of genes encoding particular cry and phy indicated that the dormancy was alleviated by the constant presence of BL or white light $\left(180 \mu \mathrm{mol} \mathrm{m} \mathrm{m}^{-2} \mathrm{~s}^{-1}\right)$ in all tested types of seeds except phyB (Figure $2 \mathrm{c}, \mathrm{d}$ ). Based on that, it is proposed that, among cry and phy, the primary role in BL-mediated dormancy alleviation plays phyB, which by its own induced cascade of reactions (i.e., via interaction with PIL5) may lead to modulation of expression of downstream genes related to phytohormones metabolism and/or signaling. This assumption is supported by earlier studies, where it was demonstrated that light activates the degradation of PIL5 protein to promote germination through GA in Arabidopsis seeds [3,39]. Our research on BL-mediated dormancy alleviation of Arabidopsis seeds clearly shows that $\mathrm{BL}$ induces changes at the molecular level, altering transcription of specific genes, i.e., involved in light, GA/ABA metabolism, and/or signaling, and that phyB plays an important role in this process.

\subsection{The phy-cry-Related Mechanism of Blue Light Action in Dormancy Alleviation and Germination of Arabidopsis Seeds Requires Interaction with Various Regulatory Proteins}

The mechanism of cry action and its activity regulation in germinating seed has not been yet thoroughly understood. Up to date, it is known that, in plants under the influence of BL, cry undergo conformational changes, which allows them to interact with a number of specific protein regulators. To decipher in more details the role of genes coding proteins interacting with cry, the expression patterns of particular genes, such as CIB1, CIB5, PHR2, PP7, and SUB1, were investigated (Figure 3). The results of expression analysis of both $C I B$ genes showed that the level of their transcripts in subsequent stages of germination of WT dormant seeds is stimulated by both BL and white light (Figure 3a,b). A different tendency was observed in the dark, where $C I B$ expression gradually decreased during incubation (Figure 3a,b). The level of CIB1 and CIB5 transcripts in WT dormant seeds incubated under BL was intermediate between the level of expression in darkness and white light. These results suggest that both $C I B$ genes may play an important role in transduction of BL-induced signal in germinating dormant seeds. Among the other genes involved in the transduction of the signal induced by BL, of which the expression was analyzed in this work, are SUB1, PHR2, and PP7. It is currently unknown whether and what biological functions these genes can play in regulation of dormancy alleviation and germination by BL. However, since they are associated with BL-related signaling, an attempt was made to characterize their role in BL-dependent germination of WT dormant Arabidopsis seeds. The regulation of BL-dependent photomorphogenesis by SUB1 probably relies on the inhibition of the accumulation of transcription factor HY5 [40]. The analysis of SUB1 expression in WT dormant Arabidopsis seeds showed that, during germination in the presence of BL and white light, the level of SUB1 transcripts was increasing while, in darkness, was downregulated (Figure 3e). The next investigated gene, $P H R 2$, encodes the protein which has photolytic activity regulated by BL [41]. The expression of the PHR2 gene in WT dormant seeds dependent on light conditions (Figure 3c). It was downregulated in darkness while kept at a stable, relatively high level in BL and upregulated by light (Figure 3c). The results of research carried out in this work suggests the possible PHR2 participation in BL-mediated dormancy alleviation of WT dormant Arabidopsis seeds. Another gene involved in the signaling of BL analyzed in this work was $P P 7$, encoding a protein with the function of serine-threonine phosphatase [42]. The results of the analysis of PP7 expression in germinating WT dormant Arabidopsis seeds showed that the level of its expression was not modulated by light conditions but was rather characterized by a constant level and only slightly increased in the later hours of germination (Figure 3d). Based on these results, the role of the PP7 gene in the regulation of light-dependent dormancy alleviation cannot be unequivocally determined.

The plant photoreceptors cry and phy, after absorbing light impulse, induce many protein-protein interactions, i.e., CUL4 E3 ubiquitin ligase with key targets, such as transcription factors (i.e., HY5, HYH, HFR1, and LAF1), resulting in changes in expression profiles of defined genes and therefore modulation of whole metabolism of plant organisms. Affinity purification of CUL4 from mammalian cells 
identified various possible substrate receptors, including COP1 known to repress light signaling by targeting photoreceptors and downstream transcription factors for ubiquitination and proteasomal degradation $[43,44]$. In consequence, the influence of light activated cry and phy on COP1 enables modulation of specific light-related gene expression. Surprisingly, there are no data in the scientific literature about the role of COP1 gene in light-dependent germination of dormant dicot seeds. The results of qRT-PCR analysis presented in this particular study indicated that light, especially the BL wavelength, stimulated COP1 expression in germinating WT dormant Arabidopsis seeds, with the higher impact at the later phases of this process, just before radical protrusion through layers covering an embryo (Figure 3f). This finding is confusing in the context of previously published data by Deng et al. [45], who demonstrated that, in Arabidopsis seedlings, mRNA level of COP1 was not dependent on light conditions and that the COP1 activity plays a more important role in regulation of this process. Taking into account that, in germinating WT dormant seeds, the light-dependent regulation of COP1 expression was observed, it is postulated that, at the time proceeding the shift from heterotrophic (germinating seed) into phototropic stage (the seedling growth), the mechanism may function differentially, as it require also changes in COP1 transcript levels. It is also possible that COP1 activity in seeds is regulated by changing the location from nuclear to cytoplasmic according to the dark or light conditions or through regulation systems associated with cry1 and cry2, as is the case in photosynthetic organs $[46,47]$. Moreover, there are evidences that cry conformation changes and that their activation occurs only under the influence of $\mathrm{BL}$, thanks to which they can inhibit the activity of attached COP1, while in the dark, COP1 not inactivated by cry can perform ubiquitination of cry, causing degradation of this photoreceptors [48]. These reactions can be an example of a possible two-way deactivation mechanism of COP1 and cry in response to the absence or presence of BL in germinating WT dormant Arabidopsis seeds.

\subsection{HY5 Transcription Factor is the Most Probably Involved in Modulation of Blue Light-Mediated Dormancy} Alleviation of Arabidopsis Seeds

In continuation of the elucidation of the role of particular elements of light signalling involved in control of dormancy alleviation and germination of WT dormant Arabidopsis seeds, the relative expression of genes coding transcription factors cooperating with cry and phy, such as HY5, HYH, $H F R 1$, and LAF1, was investigated. It was proven that these transcription factors participate in COP1-dependent plant photomorphogenesis, regulating gene expression by binding to their G-box-containing promoter sequences [26,40]. The results presented in this particular study indicated that transcript levels of $H Y 5, H Y H$, and HFR1 in germinating WT dormant seeds depended on light availability (Figure $4 a-c)$. The expression of these three genes in seeds incubated in darkness was very low, while under BL and white light, their transcript level was high. In addition, the transcript levels of HY5, HYH, and HFR1 during seed incubation exposed to BL and white light were similar; therefore, it can be assumed that it is mainly BL light (as a part of white light spectrum) that induces their expression. Interestingly, in the case of LAF1 gene, many different expression patterns were observed, with the tendency that the highest expression was in seeds incubated in darkness while the presence of BL and white light was correlated with its lower level (Figure $4 \mathrm{~d}$ ). The possible involvement of HY5, HYH, HFR1, and LAF1 in the mechanism of BL-mediated dormancy alleviation was verified in germination assays of dormant seeds of Arabidopsis WT, T-DNA insertion mutants, and transformants characterized by overexpression of these genes (Figure 4e). It was observed that all these seeds did not germinate in darkness. Surprisingly, the constant presence of BL or white light $\left(180 \mu \mathrm{mol} \mathrm{m}{ }^{-2}\right.$ $\mathrm{s}^{-1}$ ) alleviated dormancy in all tested types of seeds except 35S:OE:HY5. Moreover, the BL effect on dormancy alleviation was significantly stronger in the case of seeds of hy5 mutant (Figure 4e). It seems that an increase in HY5 expression observed in samples isolated from WT dormant seeds exposed to BL is not correlated with HY5 protein accumulation and/or increase of its activity as seeds of 35S:OE:HY5 are unable to germinate in the presence of light (Figure 4a). Hence, the transcription factor encoded by HY5 together with phyA pretend to be negative regulators of dormancy alleviation mediated by BL 
(but also white light based on the presented here in data), controlling transcript level of genes involved in ABA signaling (ABI3, ABI5, HAI1, HAI2, and HAI3), ABA metabolism (XERICO, ABA1, NCED6, NCED9, and KAO2), GA degradation (GA2ox2 and GA2ox6), and GA signaling (GID1a and GID1c) (Figure 10). Opposed to phyA and HY5, phyB is recognized as positive regulator of BL-mediated dormancy release. Based on these results, it postulated that BL received by phyB alleviates dormancy of Arabidopsis seeds via HY5-dependent modulation of expression of downstream genes related to light, GA, and ABA, while biological functions of HYH and HFR1 are associated with regulation of germination potential (Figure 10).

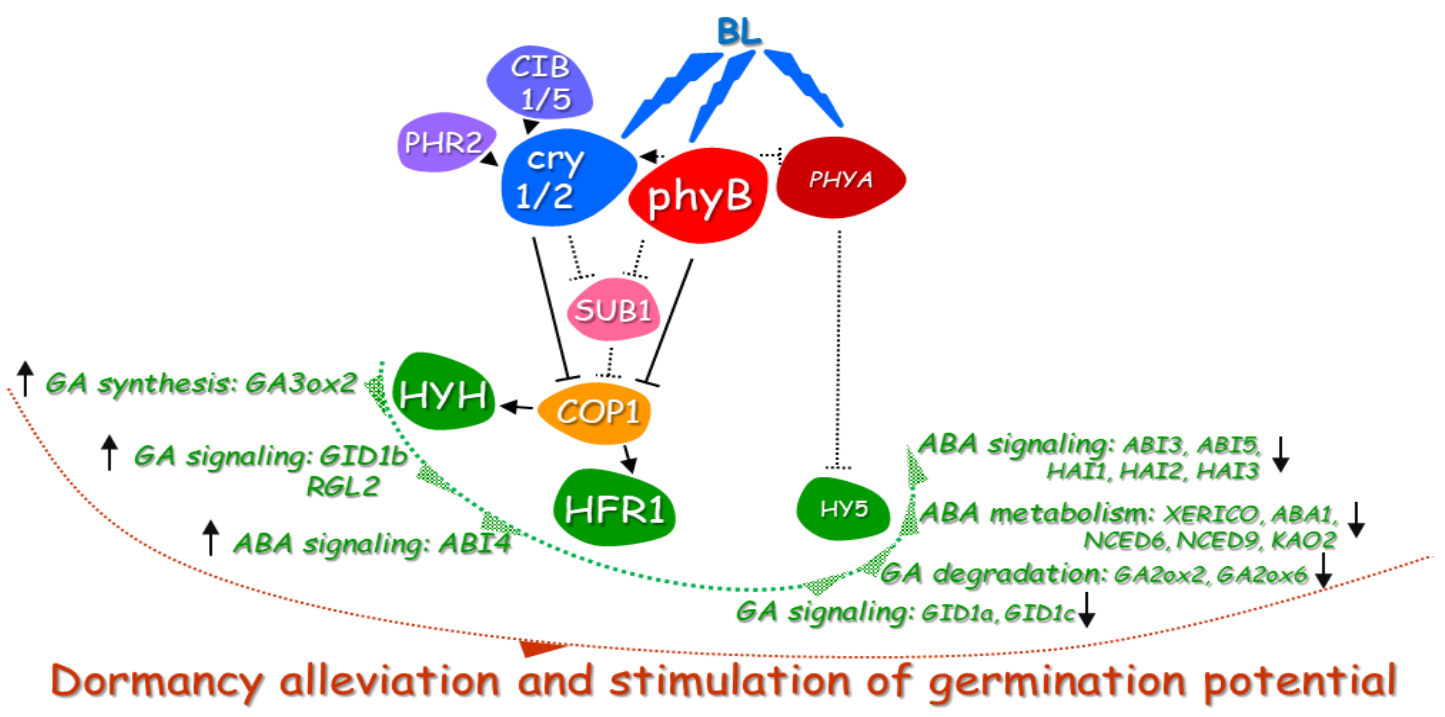

Figure 10. The hypothetical model of BL action in regulation of dormancy alleviation and germination potential of dormant Arabidopsis seeds: The BL downregulates the expression of PHYA but not PHYB neither $C R Y 1 / 2$ photoreceptors. Decreased PHYA expression is associated with a possible low HY5 accumulation and/or its activity, leading to direct or indirect decrease in expression of genes encoding dormancy related genes. On the other hand, as the effect of BL illumination on the phyB and cry $1 / 2$ controlled by phyB, CIB1/5, and PHR2, the SUB1 and COP1 activity is suppressed, leading to HYH—and HFR1-mediated activation of expression of specific genes involved in metabolism and signaling of GA and ABA, resulting in increase of germination potential. Dotted lines indicate hypothetical, possible interactions. Black arrows next to GA- and ABA-related genes indicate up- and downregulation of their expression.

\subsection{Effect of Blue Light on GA and ABA Metabolism in Germinating Dormant Seeds of Arabidopsis}

The effect of R/FR light on germinability of dicot seeds such as Arabidopsis is usually related to changes in phytohormones (i.e., ABA and GA) content and/or signaling and generally associated with phytochromes activity, mostly phyA and phyB $[19,20]$. The stimulating effect of GA on Arabidopsis seed germination has long been shown, and the role of ABA in dormancy induction and maintenance has been also well documented by genetic and physiological studies $[6,15]$. In the case of BL, it is known that it inhibits germination of dormant grains and that this mechanism involves changes in gene expression leading to increase in ABA level and reduction of GA content and/or signaling [28]. The data presented in this study for the first time indicated that BL stimulates germination of freshly harvested WT dormant Arabidopsis seeds in the manner dependent on the depth of dormancy (Figure 1). Therefore, in subsequent studies, it was considered interesting to examine if the mechanism of BL action in regulation of WT dormant Arabidopsis seeds dormancy alleviation is due to modulation of metabolism and/or signaling of GA/ABA. From the literature, it is known that WT dormant Arabidopsis seeds are characterized by high level of ABA and that the their ability to synthesize GA is crucial for starting germination process [49,50]. The treatment of germinating WT dormant Arabidopsis seeds by 
ABA and PAC (inhibitor of GA synthesis) solutions in the presence of BL or darkness indicated that the BL effect on seed germination was strongly inhibited by the presence of both substances (Table 1). These results allowed us to conclude that the mechanism of action of BL involves the regulation of GA/ABA metabolism and/or their signaling pathways.

To further elucidate the stated above hypothesis, the expression profiles of genes related to GA and ABA metabolism were characterized. Three important genes involved in biosynthesis of GA level in germinating seeds are GA3ox1, GA3ox2, and KAO2 [3,19]. In this study is shown that BL increased the level of transcript GA3ox2 while did not significantly influence GA3ox1 expression in comparison to the effect observed in darkness (Figure 5b). The expression of KAO2 gene was at a similar level in WT dormant seeds exposed to all light conditions, with an exception of a much higher $K A O 2$ expression in WT dormant seeds incubated in darkness for $48 \mathrm{~h}$ (Figure S1). Based on that, it is postulated that possible altered GA content in WT dormant seeds germinating the presence of BL may partially result from increased expression of GA3ox2 and not GA3ox1 and KAO2. Due to the fact that, in germinating seeds, the content of GA is the result of biosynthesis and degradation processes, the expression of genes belonging to GA2ox was also investigated (Figure 5a). It was observed that, after $20 \mathrm{~h}$ of incubation, the transcript level of GA20x2 was much lower under BL and white light in comparison to darkness. Although this pattern changed during later steps of germination, it is possible that especially in early stages of germination, light-dependent inhibition of GA degradation is important for induction of BL-mediated dormancy alleviation and germination processes.

The investigation of expression of genes involved in ABA metabolism showed that transcript levels of $A B A 1, N C E D 6$, and NCED9 genes depend on the light conditions as it was much higher in WT dormant seeds incubated in darkness and much lower in the presence of BL and white light (Figure 8a-c). In the case of CYP707A2, it is also possible that the decrease in transcript level of this gene is more related to duration of incubation than to light conditions. It is known that some of these genes such as NCED6 and catabolism-like CYP707A2 are known to be regulated mostly by phy so its expression is related to R/FR light signaling [19]. On the other hand, there are evidences that, in dormant barley grains, BL perceived mostly by cry1 induced the expression of NCED9 and limited expression of $A B A 8$ [28]. These findings support the assumption that BL may be one of the most important environmental factors that suppress dormant grains germination while in freshly harvested seeds of Arabidopsis this mechanism occurs in the opposite manner. All taken together, they support the statement that the BL-mediated dormancy alleviation of WT dormant seeds is related also to regulation of expression of genes involved in ABA metabolism.

The research studies aiming to decipher the mechanisms of regulation of GA and ABA metabolism have proved that these hormones can mutually regulate their own balance in germinating seeds. One of the most interesting gene involved in this kind of regulation is XERICO, a positive regulator of ABA synthesis that itself is negatively regulated by GA in DELLA-dependent manner [51]. Our results show that XERICO expression is related to light conditions and that, in germinating, WT dormant seeds is significantly lower in BL and white light conditions (Figure 7). This may suggest that XERICO is one of the genes involved in the BL-mediated dormancy alleviation and seed germination. Moreover, it indirectly shows that, under BL, there are possibly more GA which decrease XERICO expression under BL compared to darkness.

\subsection{Effect of Blue Light on GA and ABA Signaling in Germinating Dormant Seeds of Arabidopsis}

The mechanisms controlling light-dependent dicot seed germination include modulation of signaling pathways induced by phytohormones. This comprises changes in expression of GA and ABA signaling genes and/or proteins activity [3]. The regulatory proteins important for control of seed germination are GID1 receptors of GA that are responsible for GA-dependent degradation of other important signaling proteins-DELLAs [21,52]. Therefore, it was tempting to verify if BL may modulate expression of three genes belonging to GID family and, in consequence, alter GA signaling pathway during germination of WT dormant Arabidopsis seeds. Obtained results indicated that expression of 
GID1a and GID1c was downregulated by BL (Figure 6a). It is not surprising as there are evidences demonstrating that GA regulates GID1a expression through negative feedback loop [53]. In the case of RGL genes encoding DELLA proteins, the relative expression of RGL1 and RGL3 was much lower than $R G L$, and not modified in the presence of BL. These data may suggest that RGL1 and RGL3 are not involved in BL-dependent germination of WT dormant seeds. It is known that RGL1 and RGL3 are negative regulators of seed germination. Interestingly, the expression profile of $R G L 2$ indicated that its transcript level was maintained at a high level in the presence of BL at the early and later stages of germination (Figure 6b). These data may expand existing knowledge about the role of RGL2, which is actually recognized as a negative regulator in R/FR-dependent germination of Arabidopsis. It is possible that, in the presence of $\mathrm{BL}$, the protein encoded by RGL2 plays a different role. To decipher in more detail potential interactions between GA and light related pathways in WT dormant germinating seeds, the effect of GA treatment on expression of genes involved in this phytohormone signaling was determined (Figure 6c). Interestingly, the GA treatment of WT dormant seeds incubated in darkness resulted in a decrease of all GID transcripts while had a stimulatory effect on RGL2. On the other hand, the effect of GA application in the presence of white light resulted in an increase in GID1a and RGL2 expression, while in darkness GID1b and GID1c were downregulated, but the negative effect was not as strong as that observed in darkness (Figure 6c). It is also worth to notice that, for all tested genes involved in metabolism and signal transduction of GA, the changes in expression caused by BL and white light were very similar. This may suggest that signal perception and transduction induced by BL and white light leading to these changes have identical molecular and biochemical background. Based on this information, we can presume that the mechanism of dormancy alleviation and stimulation of germination of WT dormant Arabidopsis seeds by BL includes regulation of GA perception and signal transduction due to the modulation of transcripts of GID and RGL2 genes.

The studies on the role of BL light in modulation of ABA signaling during WT dormant Arabidopsis seeds germination revealed that expression of genes involved in this pathway depends on light conditions and that this specific patterns of expression can be responsible for decrease in ABA sensitivity and/or increase of GA content in WT dormant seeds germinating under BL (Figure 9). Among transcription factors from $A B I$ family, we found two, $A B I 3$ and $A B I 5$, to be downregulated by BL and white light (Figure 9a). Surprisingly, the opposite pattern was observed in the case of $A B I 4$, as its transcript level was downregulated in darkness. With regards to ABA, it was demonstrated that its signaling in germinating Arabidopsis seeds depends on light conditions, i.e., $\mathrm{R}$ light, can activate pathways leading to destabilization or degradation of ABA signaling factors such as ABI3 or ABI5 (ABA Insensitive 3 or 5), in consequence resulting in inhibition of ABA signaling and stimulation of germination process [54-56]. The protein encoded by ABI4 is known to be involved in ABA and GA crosstalk [57]. Upregulation of $A B I 4$ was previously observed, but it was correlated with increase of CYP707A2 and two DELLA genes (RGL1 and RGL3) and was phyA dependent [57]. Our data suggest that different $A B I$ genes can play different roles during BL light-dependent seed germination and that these issues need to be further investigated. The signaling pathway of ABA includes also a protein phosphatase 2C, encoded by three HAI genes. Previous studies clearly indicate that products of $H A I$ genes are important components (negative regulators) of ABA signaling pathway and interact with ABI $[57,58]$. The analysis made by us shows that expression of all HAI is light dependent (Figure $9 b$ ). The significantly lower expression of $H A I$ genes was observed in seeds germinating under BL and white light, compared to darkness. Taking together all these results characterizing expression of ABA signaling genes, it was concluded that HAI genes may have significant influence on modulation of ABA sensitivity in seeds germinating in these conditions. Therefore, we can summarize that mediated by BL dormancy alleviation and stimulation of WT dormant Arabidopsis seeds, germination is related not only to changes in expression of genes related to GA and ABA metabolism but also to their signaling pathways. 


\section{Materials and Methods}

\subsection{Plant Material and Germination Assays}

Arabidopsis thaliana ecotype Columbia (Col-0) wild type (WT) and homozygous lines of transformants characterized by overexpression of a specified gene (HY5, At5g11260; HYH, At3g17609; HFR1, At1g02340; and LAF1, At4g25560), T-DNA insertion single mutants (phyA, salk_020360; phyB, salk_022035; cry1, salk_042397; cry3, salk_085913; hfr1, salk_049497; hy5 salk_056405; and laf1, salk_079609), as well as double mutant of cry1cry2 in background Ler-0 were used in this study. The WT and insertion single mutant seeds were purchased from NASC (The Nottingham Arabidopsis Stock Center, http://arabidopsis.info/), transformants lines were generated and selected as part of this research according to the protocol described below. The double mutant of cry1cry 2 was provided by Margaret Ahmad and previously described by Ahmad et al. [59]. The T-DNA mutants were genotyped according to the protocol provided by NASC at http://signal.salk.edu/. The homozygous lines 35S:OE:HY5, 35S:OE:HYH, 35S:OE:HFR1, and 35S:OE:LAF1 were selected and verified as described in Section 4.2. In all qRT-PCR analyses as well as in most of genetic and biological studies seeds in Arabidopsis Col-0 ecotype were used. The only exception was the germination assay of mutants of genes encoding particular photoreceptors, where additionally to WT Col-0 and phyA, phyB, and cry1, cry3 in the Col-0 ecotype and WT Ler-0 and cry1cry 2 in the Ler-0 ecotype were used (results presented in Figure 2d).

Seeds were propagated from plants growth in soil mixed with perlit $(4: 1, \mathrm{v}: \mathrm{v})$ in controlled conditions in a phytochamber: long day photoperiod (16 h of light and $8 \mathrm{~h}$ of darkness) at $22^{\circ} \mathrm{C}$. Freshly harvested seeds were divided in two parts: one was stored in darkness at $-30{ }^{\circ} \mathrm{C}$ to prevent dormancy alleviation (dormant seeds), and the other one was stored in the dark at $22^{\circ} \mathrm{C}$ for at least 8 weeks to allow dormancy release (afterripened, nondormant seeds).

Seeds characterized by different depths of dormancy were sown on Petri dishes (100 seeds per plate, two technical repetitions $x$ three independent biological replicates) filled with two layers of filter paper (EUROCHEM BGD, Tarnow, Poland) in the presence of $2.7 \mathrm{~mL}$ of sterile MiliQ water and/or appropriate solution of chemicals, such as ABA (SIGMA-ALDRICH, MI, USA) and/or PAC-an inhibitor of GA synthesis (SIGMA-ALDRICH) at constant temperature of $25^{\circ} \mathrm{C}$. To avoid pathogen infections, the PPM (Plant Preservative Mixture, Plant Cell Technology, Washington, DC, USA) was added to each germination medium $(0.01 \% ; v / v)$. Seeds were germinated under different light conditions: white light (intensity $=180 \mu \mathrm{mol} \mathrm{m}{ }^{-2} \mathrm{~s}^{-1}$, source: lamps PANASONIC FL40SS), BL (range of intensities = 20-180 $\mu \mathrm{mol} \mathrm{m}^{-2} \mathrm{~s}^{-1}$, source: LED SL 3500 lamp, Photon System Instruments, Brno, Czech Republic), or darkness. The BL was emitted with optimum wavelength of $447 \mathrm{~nm}$. For checking if BL effect can be reversed by FR, impulse seeds were treated with impulse of FR light $\left(60 \mu \mathrm{mol} \mathrm{m}^{-2} \mathrm{~s}^{-1}, \lambda 735 \mathrm{~nm}\right)$ supplied from LED SL 3500 lamp (Photon System Instruments, Brno, Czech Republic) for 5 min, after $12 \mathrm{~h}$ of imbibition under BL, seeds were transferred under BL immediately after sowing.

Protrusion of the endosperm and seed coat by elongated radicle was considered as the end of germination.

\subsection{Construct Preparation, Plant Transformation, and Phenotypic Analysis of Transgenic Plants}

The specific primers were designed to amplify coding sequences of 4 genes of transcription factors, such as HY5 (L: CACCATGCAGGAACAAGCGACTA, R: TCAAAGGCTTGCATCAGCAT), HFR1 (L: CACCATGTCGAATAATCAAGCTTTC, R: TCATAGTCTTCTCATCGCA), HYH (L: CACCATGTCTCTCCAACGACCCA, R: TTAGTGATTGTCATCAGTTTTAGG), and LAF1 (L: CACCATGGCGAAGACGAAATATGGA, R: TTACGTCGTTGTTGATGGAGAA). All coding sequences of the indicated above genes were fused behind the cauliflower mosaic virus 35S promoter of the Agrobacterium tumefaciens using $\mathrm{pENTR}$ TM/D-TOPO (Invitrogen, Waltham, MA, USA) and pK7WG2D,1 (Invitrogen) vectors by Gateway ${ }^{\mathrm{TM}}$ LR Clonase $^{\mathrm{TM}}$ II Enzyme MIX kit (Invitrogen). The plasmid constructs were mobilized into the Agrobacterium strain EHA and transformed into WT Arabidopsis Col-0 plants by the floral dip method, as described by Clough and Bent [60]. After that step, 
T1 seeds were bulk collected and plated on Murashige and Skoog (MS) medium (SIGMA-ALDRICH), supplemented with $1 \%$ sucrose and $75 \mathrm{mg} / \mathrm{mL}$ kanamycin. Antibiotic-resistant F1 plants were identified after 10-14 days in a growth phytochamber. Then, they were transferred to a soil mixed with perlit $(4: 1, v: v)$ and allowed to grow and self-pollinate. The T2 progeny of individual T1 plants were harvested and analyzed further. At least 100 seeds of transgenic T2 and T3 lines were sown on MS plates containing $1 \%$ sucrose and $75 \mathrm{mg} / \mathrm{mL}$ kanamycin, cold treated at $8{ }^{\circ} \mathrm{C}$ for 4 days, and allowed to germinate by 4 days under constant white light (intensity $=180 \mu \mathrm{mol} \mathrm{m}^{-2} \mathrm{~s}^{-1}$ ) at $22^{\circ} \mathrm{C}$ before being transferred to the long day photoperiod ( $16 \mathrm{~h}$ of light and $8 \mathrm{~h}$ of darkness) at the same temperature conditions.

The levels of expression of HY5, HYH, HFR1, and LAF1 in corresponding to them obtained homozygous lines of transformants. T-DNA insertion mutants hfr1, hy5, and laf1 were verified by qRT-PCR method using primers characterised in Table S2, and the results are presented in the Figures S2 and S3.

\subsection{RNA Extraction and $C D N A$ Synthesis}

The samples of RNA used further for cDNA synthesis and qRT-PCR analysis of genes expressions were extracted from WT dormant Arabidopsis seeds imbibed for 20, 36, or 48 hours under constant light conditions: darkness, BL $\left(180 \mu \mathrm{mol} \mathrm{m}^{-2} \mathrm{~s}^{-1}\right)$, and white light $\left(180 \mu \mathrm{mol} \mathrm{m}{ }^{-2} \mathrm{~s}^{-1}\right)$. Collected seeds were immediately frozen in liquid nitrogen and grinded using a tissuelyser (Precellys 24, Bertin Technologies, Montigny-le-Bretonneux, France). The total RNA was extracted using the CTAB method described previously by Chang et al. [61] and Cadman et al. [62]. Before cDNA synthesis, extracted RNA was treated with DNase I (SIGMA-ALDRICH) to eliminate any potential residues of plant genomic DNA. The cDNA was synthetized from $1.8 \mu \mathrm{g}$ of total RNA of each biological sample, using Revert Aid H Minus First Strand cDNA Synthesis Kit (Thermo Fisher Scientific, Waltham, MA, USA) according to the manufacturer's protocol in a thermocycler NEXUS (Eppendorf, Hamburg, Germany). The concentration and purity of RNA was validated on Nanodrop 2000 (Thermo Fisher Scientific), while RNA integrity was checked by the electrophoresis in $1 \%$ agarose gel.

\subsection{Quantitative Real Time-PCR Analysis}

The quantitative Real Time-PCR analysis was performed using SybrGreen Master Mix (ROCHE, Basel, Switzerland) and $200 \mathrm{ng}$ of cDNA as a template. Reactions were run on LightCycler' 96 (ROCHE, Basel, Switzerland). The relative expressions of following genes were analysed: 1) light signaling related genes: PHYA (At1g09570), PHYB (At2g18790), CRY1 (At4g08920), CRY2 (At1g04400), CRY3 (At5g24850), HY5 (At5g11260), HYH (At3g17609), HFR1 (At1g02340), LAF1 (At4g25560), CIB1 (At4g34530), CIB5 (At1g26260), SUB1 (At4g08810), PP7 (At5g63870), PHR2 (At2g47590), and COP1 (At2g32950); 2) genes involved in ABA metabolism and signalling: ABA1 (At5g67030), NCED6 (At3g24220), NCED9 (At1g78390), CYP707A2 (At2g29090), ABI3 (At3G24650), ABI4 (At2G40220), ABI5 (At2G36270), HAI1 (At5g59220), HAI2 (At1g07430), and HAI3 (At2g29380); and 3) genes involved in GA metabolism and signalling: GA3ox1 (At1g15550), GA3ox2 (At1g80340), GA2ox6 (At1g02400), GA2ox2 (At1g30040), GID1a (At3g05120), GID1b (At3g63010), GID1c (At5g27320), RGL1 (At1g66350), RGL2 (At3g03450), RGL3 (At5g17490), XERICO (At2g04240), and KAO2 (At2g32440). The characteristic of gene-specific primers used in qRT-PCR is shown in Table S2. The primers were designed using the Primer3 program (http://www.bioinformatics.nl/cgibin/primer3plus/primer3plus.cgi). The coding nucleotide sequences of investigated genes was taken from the NCBI database (http://www.ncbi.nlm.nih.gov/). In addition, analysis of homologous sequences was performed using the ClustalW program (http: //www.ebi.ac.uk/Tools/msa/clustalw2/), and primer pairs were designed that were specifically bound to the sequence of the selected gene. The obtained results were calculated using tree reference genes: ACT7 (ACTIN7, At5g09810), APC2 (ANAPHASE PROMOTING COMPLEX/CYCLOSOME 2, At2g04660), and HBT (HOBBIT, At2g20000), described as genes with stable expression in germinating Arabidopsis seeds [63]. The values of relative expression obtained for each analysed gene in samples obtained from 
seeds after $20 \mathrm{~h}$ of imbibition in darkness was recognized as 1 . On the graphs, the relative expression of genes is shown.

For studying the impact of GA on different GID1 and RGL2 genes, dormant Arabidopsis Col-0 seeds were treated for $20 \mathrm{~h}$ with GA in concentration of $50 \mu \mathrm{M}$ at constant temperature of $25^{\circ} \mathrm{C}$ in darkness or under white light (intensity $=180 \mu \mathrm{mol} \mathrm{m} \mathrm{m}^{-2} \mathrm{~s}^{-1}$ ). The results were expressed as $\%$ of relative transcript levels presented in seeds imbibed on water \pm SD.

\subsection{Statystical Analysis}

The obtained results were analyzed using Statistica 13.1 Software (Statsoft, Cracow, Poland). The mean values were calculated, and statistically significant differences were evaluated using ANOVA analysis followed by Tukey's HSD post hoc test for germination assays $\left({ }^{*} p \leq 0.05 ;{ }^{* *} p \leq 0.01\right)$ and qRT-PCR analysis of GA treated WT dormant Arabidopsis (Col-0) seeds ( $\mathrm{p} \leq 0.05)$. The ANOVA analysis and Duncan's post hoc test were used to determine homogeneous groups in qRT-PCR analysis of WT dormant Arabidopsis (Col-0) seeds incubated on water for 20,36, and $48 \mathrm{~h}$ in different light conditions (BL and white light and darkness) ( $\mathrm{p} \leq 0.05)$. Standard deviation $( \pm \mathrm{SD})$ was also provided to indicate the variations associated with the particular mean values.

\section{Conclusions}

Based on obtained data, the hypothetical model of possible BL mechanism of action in regulation of dormancy alleviation and germination potential of Arabidopsis seeds is proposed (Figure 10).

It is proposed that the key photoreceptors involved in dormancy alleviation mechanism mediated by BL are phyB (Figure 10). The phyB by its own induced cascade of reactions but also by influencing cry1/2 activities may suppress the SUB1 and COP1 actions to modulate expression of genes encoding transcription factors, such as $H Y H$ and HFR1, leading to increase in transcript levels of downstream genes involved in GA synthesis (GA3ox2), GA signaling (GID1b and RGL2), and ABA signaling (ABI4). Besides of the phyB influence on cry $1 / 2$ action, CIB1/5 and PHR2 proteins may also have a positive effect on cry1/2 activities as the expressions of genes CIB1/5 and PHR2 are upregulated by BL. On the other hand, as the effect of BL-induced signal, the expression of PHYA decreases, which together with the possible inhibitory effect of phyB on phyA activity results in increase of HY5 expression but not HY 5 protein accumulation and/or increase of its activity. The transcription factor encoded by HY5 seems to be a negative regulator of dormancy alleviation and germination mediated by BL (but also white light based on the presented data), controlling transcript level of genes involved in ABA signaling (ABI3, ABI5, HAI1, HAI2, and HAI3), ABA metabolism (XERICO, ABA1, NCED6, NCED9, and KAO2), GA degradation (GA2ox2 and GA2ox6), and GA signaling (GID1a and GID1c). All taken together result in dormancy alleviation by BL and increase in germination potential of Arabidopsis seeds (Figure 10).

Supplementary Materials: Supplementary materials can be found at http://www.mdpi.com/1422-0067/20/23/ 5882/s1.

Author Contributions: Conceptualization, K.O.; methodology, K.O.; validation, K.O.; formal analysis, K.O.; investigation, M.S. and K.O.; resources, K.O.; data curation, K.O.; writing-original draft preparation, K.O. and M.S.; writing—review and editing, K.O.; visualization, M.S. and K.O.; supervision, K.O.; project administration, K.O.; funding acquisition, K.O.

Funding: This research was funded by the National Science Centre (Poland), grant SONATA2 number: 2011/03/D/NZ9/04059, and grant PRELUDIUM12 (number 2016/23/N/NZ3/02239).

Conflicts of Interest: The authors declare no conflict of interest. 


\section{Abbreviations}

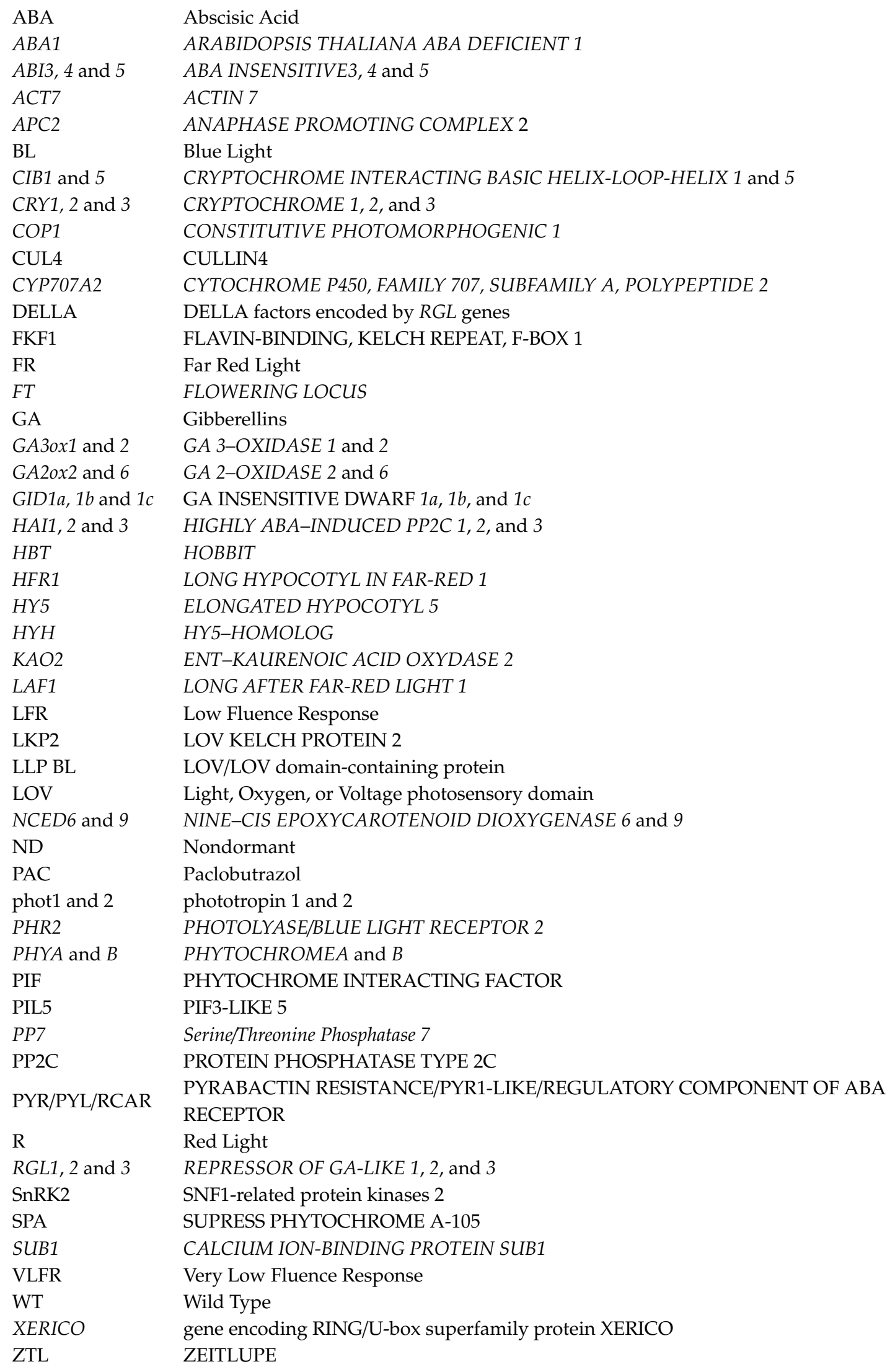




\section{References}

1. Song, J.; Liu, Q.; Hu, B.; Wu, W. Photoreceptor PhyB Involved in Arabidopsis Temperature Perception and Heat-Tolerance Formation. Int. J. Mol. Sci. 2017, 18, 1194. [CrossRef] [PubMed]

2. Mérai, Z.; Graeber, K.; Wilhelmsson, P.; Ullrich, K.K.; Arshad, W.; Grosche, C.; Tarkowská, D.; Turečková, V.; Strnad, M.; Rensing, S.A.; et al. Aethionema arabicum: A novel model plant to study the light control of seed germination. J. Exp. Bot. 2019, 70, 3313-3328. [CrossRef] [PubMed]

3. Seo, M.; Nambara, E.; Choi, G.; Yamaguchi, S. Interaction of light and hormone signals in germinating seeds. Plant Mol. Biol. 2009, 69, 463-472. [CrossRef] [PubMed]

4. Huang, Z.; Footitt, S.; Tang, A.; Finch-Savage, W.E. Predicted global warming scenarios impact on the mother plant to alter seed dormancy and germination behaviour in Arabidopsis. Plant Cell Environ. 2018, 41, $187-197$. [CrossRef] [PubMed]

5. Leymarie, J.; Vitkauskaité, G.; Hoang, H.H.; Gendreau, E.; Chazoule, V.; Meimoun, P.; Corbineau, F.; El-Maarouf-Bouteau, H.; Bailly, C. Role of Reactive Oxygen Species in the Regulation of Arabidopsis Seed Dormancy. Plant Cell Physiol. 2012, 53, 96-106. [CrossRef] [PubMed]

6. Oracz, K.; Karpiński, S. Phytohormones Signaling Pathways and ROS Involvement in Seed Germination. Front. Plant Sci. 2016, 7, 864. [CrossRef]

7. Shinomura, T.; Nagatani, A.; Chory, J.; Furuya, M. The Induction of Seed Germination in Arabidopsis thaliana Is Regulated Principally by Phytochrome B and Secondarily by Phytochrome A. Plant Physiol. 1994, 104, 363-371. [CrossRef]

8. Oracz, K.; Stawska, M. Cellular Recycling of Proteins in Seed Dormancy Alleviation and Germination. Plant Sci. 2016, 1128. [CrossRef]

9. Oracz, K.; Voegele, A.; Tarkowská, D.; Jacquemoud, D.; Turecková, V.; Urbanová, T.; Strnad, M.; Sliwinska, E.; Leubner-Metzger, G. Myrigalone A inhibits Lepidium sativum seed germination by interference with gibberellin metabolism and apoplastic superoxide production required for embryo extension growth and endosperm rupture. Plant Cell Physiol. 2012, 53, 81-95. [CrossRef]

10. Chen, M.; Chory, J.; Fankhauser, C. Light Signal Transduction in Higher Plants. Annu. Rev. Genet. 2004, 38, 87-117. [CrossRef]

11. Ito, S.; Song, Y.H.; Imaizumi, T. LOV Domain-Containing F-Box Proteins: Light-Dependent Protein Degradation Modules in Arabidopsis. Mol. Plant 2012, 5, 47-56. [CrossRef] [PubMed]

12. Zoltowski, B.D.; Imaizumi, T. Structure and function of the ZTL/FKF1/LKP2 group proteins in Arabidopsis. Enzymes 2014, 35, 213-239. [PubMed]

13. Klar, T.; Pokorny, R.; Moldt, J.; Batschauer, A.; Essen, L.-O. Cryptochrome 3 from Arabidopsis thaliana: Structural and Functional Analysis of its Complex with a Folate Light Antenna. J. Mol. Biol. 2007, 366, 954-964. [CrossRef] [PubMed]

14. Yu, X.; Liu, H.; Klejnot, J.; Lin, C. The Cryptochrome Blue Light Receptors. Arab. Book Am. Soc. Plant Biol. 2010, 8. [CrossRef]

15. Stawska, M.; Oracz, K. Sieć powiązań szlaków fitochromowych, kryptochromowych oraz indukowanych przez regulatory wzrostu i rozwoju w biologii nasion. Post. Biol. Kom. 2015, 42, 687-706.

16. Podolec, R.; Ulm, R. Photoreceptor-mediated regulation of the COP1/SPA E3 ubiquitin ligase. Curr. Opin. Plant Biol. 2018, 45, 18-25. [CrossRef]

17. Shinomura, T.; Nagatani, A.; Hanzawa, H.; Kubota, M.; Watanabe, M.; Furuya, M. Action spectra for phytochrome A- and B-specific photoinduction of seed germination in Arabidopsis thaliana. Proc. Natl. Acad. Sci. USA 1996, 93, 8129-8133. [CrossRef]

18. Saijo, Y.; Zhu, D.; Li, J.; Rubio, V.; Zhou, Z.; Shen, Y.; Hoecker, U.; Wang, H.; Deng, X.W. Arabidopsis COP1/SPA1 complex and phytochrome A signaling intermediates associate with distinct phosphorylated forms of phytochrome A in balancing signal propagation and attenuation. Mol. Cell 2008, 31, 607-613. [CrossRef]

19. Seo, M.; Hanada, A.; Kuwahara, A.; Endo, A.; Okamoto, M.; Yamauchi, Y.; North, H.; Marion-Poll, A.; Sun, T.; Koshiba, T.; et al. Regulation of hormone metabolism in Arabidopsis seeds: Phytochrome regulation of abscisic acid metabolism and abscisic acid regulation of gibberellin metabolism. Plant J. 2006, 48, 354-366. [CrossRef] 
20. Ibarra, S.E.; Auge, G.; Sánchez, R.A.; Botto, J.F. Transcriptional programs related to phytochrome A function in Arabidopsis seed germination. Mol. Plant 2013, 6, 1261-1273. [CrossRef]

21. Griffiths, J.; Murase, K.; Rieu, I.; Zentella, R.; Zhang, Z.-L.; Powers, S.J.; Gong, F.; Phillips, A.L.; Hedden, P.; Sun, T.; et al. Genetic characterization and functional analysis of the GID1 gibberellin receptors in Arabidopsis. Plant Cell 2006, 18, 3399-3414. [CrossRef] [PubMed]

22. Eckardt, N.A. GA Signaling: Direct Targets of DELLA Proteins. Plant Cell 2007, 19, 2970. [CrossRef]

23. Tischer, S.V.; Wunschel, C.; Papacek, M.; Kleigrewe, K.; Hofmann, T.; Christmann, A.; Grill, E. Combinatorial interaction network of abscisic acid receptors and coreceptors from Arabidopsis thaliana. Proc. Natl. Acad. Sci. USA 2017, 114, 10280-10285. [CrossRef] [PubMed]

24. Lian, H.-L.; He, S.-B.; Zhang, Y.-C.; Zhu, D.-M.; Zhang, J.-Y.; Jia, K.-P.; Sun, S.-X.; Li, L.; Yang, H.-Q. Blue-light-Dependent interaction of cryptochrome 1 with SPA1 defines a dynamic signaling mechanism. Genes Dev. 2011, 25, 1023-1028. [CrossRef]

25. Liu, B.; Zuo, Z.; Liu, H.; Liu, X.; Lin, C. Arabidopsis cryptochrome 1 interacts with SPA1 to suppress COP1 activity in response to blue light. Genes Dev. 2011, 25, 1029-1034. [CrossRef]

26. Wang, Q.; Zuo, Z.; Wang, X.; Liu, Q.; Gu, L.; Oka, Y.; Lin, C. Beyond the photocycle-How cryptochromes regulate photoresponses in plants? Curr. Opin. Plant Biol. 2018, 45, 120-126. [CrossRef]

27. Liu, H.; Yu, X.; Li, K.; Klejnot, J.; Yang, H.; Lisiero, D.; Lin, C. Photoexcited CRY2 Interacts with CIB1 to Regulate Transcription and Floral Initiation in Arabidopsis. Science 2008, 322, 1535-1539. [CrossRef]

28. Barrero, J.M.; Downie, A.B.; Xu, Q.; Gubler, F. A Role for Barley CRYPTOCHROME1 in Light Regulation of Grain Dormancy and Germination. Plant Cell 2014, 26, 1094-1104. [CrossRef]

29. Gubler, F.; Hughes, T.; Waterhouse, P.; Jacobsen, J. Regulation of Dormancy in Barley by Blue Light and After-Ripening: Effects on Abscisic Acid and Gibberellin Metabolism. Plant Physiol. 2008, 147, 886-896. [CrossRef]

30. Strasser, B.; Sánchez-Lamas, M.; Yanovsky, M.J.; Casal, J.J.; Cerdán, P.D. Arabidopsis thaliana life without phytochromes. Proc. Natl. Acad. Sci. USA 2010, 107, 4776-4781. [CrossRef]

31. Hofmann, N. Cryptochromes and Seed Dormancy: The Molecular Mechanism of Blue Light Inhibition of Grain Germination. Plant Cell 2014, 26, 846. [CrossRef] [PubMed]

32. Jacobsen, J.V.; Barrero, J.M.; Hughes, T.; Julkowska, M.; Taylor, J.M.; Xu, Q.; Gubler, F. Roles for blue light, jasmonate and nitric oxide in the regulation of dormancy and germination in wheat grain Triticum aestivum $\mathrm{L}$. Planta 2013, 238, 121-138. [CrossRef] [PubMed]

33. Casal, J.J.; Candia, A.N.; Sellaro, R. Light perception and signalling by phytochrome A. J. Exp. Bot. 2014, 65, 2835-2845. [CrossRef] [PubMed]

34. Neff, M.M.; Fankhauser, C.; Chory, J. Light: An indicator of time and place. Genes Dev. 2000, 14, $257-271$. [PubMed]

35. Pokorny, R.; Klar, T.; Hennecke, U.; Carell, T.; Batschauer, A.; Essen, L.-O. Recognition and repair of UV lesions in loop structures of duplex DNA by DASH-type cryptochrome. Proc. Natl. Acad. Sci. USA 2008, 105, 21023-21027. [CrossRef]

36. Kleine, T.; Lockhart, P.; Batschauer, A. An Arabidopsis protein closely related to Synechocystis cryptochrome is targeted to organelles. Plant J. Cell Mol. Biol. 2003, 35, 93-103. [CrossRef]

37. Clack, T.; Mathews, S.; Sharrock, R.A. The phytochrome apoprotein family in Arabidopsis is encoded by five genes: The sequences and expression of PHYD and PHYE. Plant Mol. Biol. 1994, 25, 413-427. [CrossRef]

38. Sharrock, R.A.; Quail, P.H. Novel phytochrome sequences in Arabidopsis thaliana: Structure, evolution, and differential expression of a plant regulatory photoreceptor family. Genes Dev. 1989, 3, 1745-1757. [CrossRef]

39. Oh, E.; Yamaguchi, S.; Kamiya, Y.; Bae, G.; Chung, W.I.; Choi, G. Light activates the degradation of PIL5 protein to promote seed germination through gibberellin in Arabidopsis. Plant J. 2006, 47, 124-139. [CrossRef]

40. Guo, H.; Mockler, T.; Duong, H.; Lin, C. SUB1, an Arabidopsis $\mathrm{Ca}^{2+}$-Binding Protein Involved in Cryptochrome and Phytochrome Coaction. Science 2001, 291, 487-490. [CrossRef]

41. Ahmad, M.; Jarillo, J.A.; Cashmore, A.R. PHR2: A novel Arabidopsis gene related to the blue-light. Plant Physiol. 1998, 117, 718-719.

42. Andreeva, A.V.; Kutuzov, M.A. Nuclear localization of the plant protein Ser/Thr phosphatase PP7. Mol. Cell Biol. Res. Commun. MCBRC 2001, 4, 345-352. [CrossRef] [PubMed] 
43. Higa, L.A.; Wu, M.; Ye, T.; Kobayashi, R.; Sun, H.; Zhang, H. CUL4-DDB1 ubiquitin ligase interacts with multiple WD40-repeat proteins and regulates histone methylation. Nat. Cell Biol. 2006, 8, 1277-1283. [CrossRef] [PubMed]

44. Jin, J.; Arias, E.E.; Chen, J.; Harper, J.W.; Walter, J.C. A Family of Diverse Cul4-Ddb1-Interacting Proteins Includes Cdt2, which Is Required for S Phase Destruction of the Replication Factor Cdt1. Mol. Cell 2006, 23, 709-721. [CrossRef]

45. Deng, X.-W.; Matsui, M.; Wei, N.; Wagner, D.; Chu, A.M.; Feldmann, K.A.; Quail, P.H. COP1, an Arabidopsis regulatory gene, encodes a protein with both a zinc-binding motif and a G $\beta$ homologous domain. Cell 1992, 71, 791-801. [CrossRef]

46. Wang, H.; Ma, L.-G.; Li, J.-M.; Zhao, H.-Y.; Deng, X.W. Direct Interaction of Arabidopsis Cryptochromes with COP1 in Light Control Development. Science 2001, 294, 154-158. [CrossRef]

47. Liu, H.; Liu, B.; Zhao, C.; Pepper, M.; Lin, C. The action mechanisms of plant cryptochromes. Trends Plant Sci. 2011, 16, 684-691. [CrossRef]

48. Yi, C.; Deng, X.W. COP1—From plant photomorphogenesis to mammalian tumorigenesis. Trends Cell Biol. 2005, 15, 618-625. [CrossRef]

49. Lefebvre, V.; North, H.; Frey, A.; Sotta, B.; Seo, M.; Okamoto, M.; Nambara, E.; Marion-Poll, A. Functional analysis of Arabidopsis NCED6 and NCED9 genes indicates that ABA synthesized in the endosperm is involved in the induction of seed dormancy. Plant J. 2006, 45, 309-319. [CrossRef]

50. Yamauchi, Y.; Ogawa, M.; Kuwahara, A.; Hanada, A.; Kamiya, Y.; Yamaguchi, S. Activation of Gibberellin Biosynthesis and Response Pathways by Low Temperature during Imbibition of Arabidopsis thaliana Seeds. Plant Cell 2004, 16, 367-378. [CrossRef]

51. Ariizumi, T.; Lawrence, P.K.; Steber, C.M. The Role of Two F-Box Proteins, SLEEPY1 and SNEEZY, in Arabidopsis Gibberellin Signaling. Plant Physiol. 2011, 155, 765-775. [CrossRef] [PubMed]

52. Murase, K.; Hirano, Y.; Sun, T.; Hakoshima, T. Gibberellin-induced DELLA recognition by the gibberellin receptor GID1. Nature 2008, 456, 459-463. [CrossRef] [PubMed]

53. Voegele, A.; Graeber, K.; Oracz, K.; Tarkowská, D.; Jacquemoud, D.; Turečková, V.; Urbanová, T.; Strnad, M.; Leubner-Metzger, G. Embryo growth, testa permeability, and endosperm weakening are major targets for the environmentally regulated inhibition of Lepidium sativum seed germination by myrigalone A. J. Exp. Bot. 2012, 63, 5337-5350. [CrossRef] [PubMed]

54. Chen, H.; Zhang, J.; Neff, M.M.; Hong, S.-W.; Zhang, H.; Deng, X.-W.; Xiong, L. Integration of light and abscisic acid signaling during seed germination and early seedling development. Proc. Natl. Acad. Sci. USA 2008, 105, 4495-4500. [CrossRef]

55. Lim, S.; Park, J.; Lee, N.; Jeong, J.; Toh, S.; Watanabe, A.; Kim, J.; Kang, H.; Kim, D.H.; Kawakami, N.; et al. ABA-INSENSITIVE3, ABA-INSENSITIVE5, and DELLAs Interact to Activate the Expression of SOMNUS and Other High-Temperature-Inducible Genes in Imbibed Seeds in Arabidopsis. Plant Cell 2013, 25, 4863-4878. [CrossRef]

56. Tang, W.; Ji, Q.; Huang, Y.; Jiang, Z.; Bao, M.; Wang, H.; Lin, R. FAR-RED ELONGATED HYPOCOTYL3 and FAR-RED IMPAIRED RESPONSE1 Transcription Factors Integrate Light and Abscisic Acid Signaling in Arabidopsis. Plant Physiol. 2013, 163, 857-866. [CrossRef]

57. Shu, K.; Zhang, H.; Wang, S.; Chen, M.; Wu, Y.; Tang, S.; Liu, C.; Feng, Y.; Cao, X.; Xie, Q. ABI4 Regulates Primary Seed Dormancy by Regulating the Biogenesis of Abscisic Acid and Gibberellins in Arabidopsis. PLoS Genet. 2013, 9, e1003577. [CrossRef]

58. Kurup, S.; Jones, H.D.; Holdsworth, M.J. Interactions of the developmental regulator ABI3 with proteins identified from developing Arabidopsis seeds. Plant J. 2000, 21, 143-155. [CrossRef]

59. Ahmad, M.; Grancher, N.; Heil, M.; Black, R.C.; Giovani, B.; Galland, P.; Lardemer, D. Action spectrum for cryptochrome-dependent hypocotyl growth inhibition in Arabidopsis. Plant Physiol. 2002, 129, 774-785. [CrossRef]

60. Clough, S.J.; Bent, A.F. Floral dip: A simplified method for Agrobacterium-Mediated transformation of Arabidopsis thaliana. Plant J. 1998, 16, 735-743. [CrossRef]

61. Chang, S.; Puryear, J.; Cairney, J. A simple and efficient method for isolating RNA from pine trees. Plant Mol. Biol. Report. 1993, 11, 113-116. [CrossRef] 
62. Cadman, C.S.C.; Toorop, P.E.; Hilhorst, H.W.M.; Finch-Savage, W.E. Gene expression profiles of Arabidopsis Cvi seeds during dormancy cycling indicate a common underlying dormancy control mechanism. Plant J. 2006, 46, 805-822. [CrossRef] [PubMed]

63. Dekkers, B.J.W.; Willems, L.; Bassel, G.W.; van Bolderen-Veldkamp, R.P.; Ligterink, W.; Hilhorst, H.W.M.; Bentsink, L. Identification of Reference Genes for RT-qPCR Expression Analysis in Arabidopsis and Tomato Seeds. Plant Cell Physiol. 2012, 53, 28-37. [CrossRef] [PubMed]

(C) 2019 by the authors. Licensee MDPI, Basel, Switzerland. This article is an open access article distributed under the terms and conditions of the Creative Commons Attribution (CC BY) license (http://creativecommons.org/licenses/by/4.0/). 